\title{
O Impacto da Internacionalização com Foco na Inovação Tecnológica sobre as Exportações das Firmas Brasileiras*
}

\author{
Glauco Arbix \\ Mario Sergio Salerno \\ João Alberto De Negri
}

\section{INTRODUÇÃO}

\begin{abstract}
A questão do desempenho das exportações brasileiras sempre esteve presente na agenda governamental e também não é nova na literatura. Mais recentemente, com a Política Industrial, Tecnológica e de Comércio Exterior do governo Lula, o tema da internacionalização de empresas brasileiras volta ao centro da cena. Uma vez que boa parte do comércio internacional se dá intrafirmas, a internacionalização de empresas e sua relação com as exportações surgem como um aspecto a
\end{abstract}

\footnotetext{
* Os autores agradecem as contribuições de Antônio Barros de Castro, Renato Baumann, Ricardo Bielschowsky, Wilson Suzigan e dos pesquisadores do Instituto de Pesquisa Econômica Aplicada - IPEA, Gilberto Hollauer, Nilton Nareto, Mansueto Almeida, Priscila Vieira e Waldery Rodrigues. Eventuais falhas e omissões são de responsabilidade dos autores. O trabalho só foi possível graças ao apoio do Instituto Brasileiro de Geografia e Estatística - IBGE, do Ministério do Desenvolvimento, Indústria e Comércio Exterior - MDIC/Secretaria de Comércio Exterior - SECEX e do Ministério do Trabalho e Emprego - MTE. O IPEA não tem a posse física das informações utilizadas neste artigo e, portanto, a realização de trabalhos como este só é possível em virtude das parcerias estabelecidas entre o IPEA, o IBGE, o MTE, o Banco Central do Brasil - BACEN, o Ministério do Planejamento, Orçamento e Gestão - MPOG e a SECEX/MDIC. O acesso às informações necessárias ao texto seguiu rigorosamente os procedimentos que garantem o sigilo de informações restritas, não sendo possível a visualização ou gravação de dados que possam vir a identificar empresas. Uma primeira versão deste artigo foi apresentada no Fórum Nacional, em 2004, sob o título “Inovação, Via Internacionalização, Faz Bem para as Exportações Brasileiras".
}

DADOS - Revista de Ciências Sociais, Rio de Janeiro, Vol. 48, nº̂1, 2005, pp. 395 a 442. 
ser investigado. Parece haver evidências de que o desempenho exportador pode ser influenciado positivamente quando a firma estabelece uma subsidiária no exterior. Esta pode contribuir com o seu desempenho exportador por exercer diversas funções, tais como acessar canais de comercialização, adaptar os produtos à demanda de mercados específicos, criar mercados, acessar recursos financeiros mais baratos e apropriar tecnologias não disponíveis no mercado doméstico.

Existe uma lacuna na literatura e nas políticas públicas brasileiras quando o tema é a internacionalização e seu impacto sobre as exportações. Este artigo procura ajudar a preencher essa lacuna. Os trabalhos até então elaborados investigam, no máximo, poucas dezenas de empresas. No presente texto, exploraremos integradamente as grandes bases de dados nacionais, quais sejam, Pesquisa Industrial Anual PIA, Pesquisa Industrial de Inovação Tecnológica - PINTEC/IBGE, SECEX/MDIC e Relação Anual de Informações Sociais - RAIS /MTE, o que possibilita análises extremamente abrangentes que alcançam mais de $90 \%$ do valor adicionado na indústria. A PINTEC apresenta uma pergunta referente à utilização de estabelecimento do grupo empresarial no exterior como fonte principal de informações para a inovação, o que permite analisar as características das firmas que realizam esse tipo específico de internacionalização, chamado assim com base na inovação. Ou seja, essa forma de internacionalização é entendida como a situação na qual a firma possui no exterior um outro estabelecimento do grupo que é utilizado como fonte principal de informação para a inovação tecnológica.

Buscam-se evidências sobre qual é a influência dessa internacionalização sobre o comércio exterior da firma. Mais especificamente, o objetivo deste trabalho é responder às seguintes perguntas: Quais são as características das firmas que realizam internacionalização com foco na inovação tecnológica na indústria brasileira? Qual é o impacto desse tipo de internacionalização no comércio exterior brasileiro? Qual é a importância relativa dos diferentes tipos de gastos em atividades voltadas para o processo de inovação tecnológica nas firmas industriais brasileiras? Qual é a importância dos recursos financeiros públicos para que as firmas possam realizar tais inovações no Brasil? Quais os parâmetros para o governo apoiar a internacionalização com foco na inovação tecnológica das firmas industriais no Brasil? 
O artigo é composto de cinco seções, incluída esta introdução. A segunda parte faz um apanhado não exaustivo sobre os trabalhos que tratam dos determinantes das exportações brasileiras e das características da internacionalização das firmas no Brasil. A terceira cumpre três objetivos: compara as características das firmas que realizaram internacionalização com foco na inovação tecnológica com as demais firmas na indústria; verifica qual o impacto dessa internacionalização no desempenho comercial das mesmas; e estima quais são as atividades mais importantes para a firma inovar. A seção seguinte mensura a importância do apoio financeiro público para que se realizem inovações tecnológicas. A última conclui procurando estabelecer parâmetros para atuação do governo no apoio à internacionalização com foco na inovação tecnológica das firmas brasileiras.

\section{EVIDÊNCIAS SOBRE AS CARACTERÍSTICAS DA INTERNACIONALIZAÇÃO DAS FIRMAS NO BRASIL}

Diversos estudos sobre os determinantes das exportações brasileiras estiveram voltados para estimação dos custos dos recursos domésticos, que é uma medida de vantagem comparativa de um país apoiada nas teorias ricardianas e H-O (Heckscher, 1919; Ohlin, 1933). Produtos que podem gerar maior quantidade de divisas com menor custo dos recursos domésticos são aqueles sobre os quais potencialmente o país possui vantagens comparativas. Vários autores, como Savasini et alii (1974), Savasini (1978), Savasini e Kume (1979), Paula Pinto (1981; 1984; 1994), Braga e Hickmann (1988), entre outros, fizeram estimativas do custo dos recursos domésticos para o Brasil. Esses estudos encontram evidências de que os setores industriais brasileiros que usam mão-de-obra de forma mais intensiva têm um custo por divisa gerada mais baixo, se comparados aos demais. Quando se separam as indústrias que utilizam mão-de-obra qualificada daquelas que usam a não qualificada, verifica-se que o custo dos recursos é menor nas indústrias que utilizam maior quantidade de mão-de-obra não qualificada por unidade exportada.

Hidalgo (1985) foi um dos pioneiros em testar empiricamente o teorema $\mathrm{H}-\mathrm{O}$ para o Brasil. Os resultados mostram que o Brasil exporta bens intensivos em mão-de-obra e importa bens intensivos em capital, o que comprovaria os resultados H-O. Lafetá Machado (1997) testou a mesma teoria para o Brasil com base na abordagem da mão-de-obra qualificada e menos qualificada ${ }^{1}$. Os resultados mostraram que o padrão de 
comércio do Brasil está de acordo com a quantidade relativa de fatores de produção que a economia desse país dispõe, ou seja, as exportações são lastreadas em bens intensivos em mão-de-obra menos qualificada.

Outros trabalhos empíricos buscaram evidências de padrões de comércio não explicados pelas teorias fundamentadas na dotação relativa de fatores. Teitel e Thoumi (1986) são enfáticos em afirmar que o fato de o Brasil e a Argentina serem países com uma boa base de recursos humanos e mão-de-obra com certo grau de qualificação lhes possibilita aproveitar o crescimento via substituição de importações, gerando um processo de industrialização diferente dos demais países em desenvolvimento. A renda per capita relativamente alta e concentrada em grandes centros urbanos e o mercado doméstico relativamente grande são capazes de evitar substanciais deseconomias de escala nesses países.

A evidência de um padrão de comércio intra-indústria ${ }^{2}$ no Brasil está presente nos trabalhos de Hidalgo (1990; 1993). Este autor identificou que, no final da década de 80, mais da metade das exportações brasileiras de manufaturados era do tipo intra-indústria. Machado (1992) também identificou a existência de um padrão de comércio intra-industrial entre o Brasil e os países de Associação Latino-Americana de Integração - Aladi. Segundo este estudo, na década de 80, a instabilidade macroeconômica que atingiu a região impediu que as indústrias estabelecessem vínculos desse tipo de comércio, e o único fluxo de comércio intra-industrial permanente que então se desenvolveu foi o intercâmbio intrafirma. Essas evidências também foram encontradas por Baumann (1993). Seus resultados indicaram que o comércio intrafirma no Brasil tinha aumentado de forma expressiva nessa mesma década e respondido por parcelas significativas das exportações em algumas indústrias.

A relação entre a estrutura industrial e a exportação de manufaturados do Brasil foi também analisada por Braga e Guimarães (1985). A particularidade deste trabalho está na base de dados que utiliza informações por firmas. Alguns resultados indicam que há evidências de que o desempenho exportador do Brasil em 1978 é explicado pela variável "escala de produção"

Os trabalhos que investigam os determinantes das exportações brasileiras utilizando informações por firmas não são freqüentes na literatura brasileira. Pinheiro e Moreira (2000) analisaram o perfil das firmas 
exportadoras brasileiras e encontraram evidências sobre os determinantes das exportações com base em dados por firmas. Esses autores encontraram que o fator que mais afeta a probabilidade da firma ser exportadora é o seu tamanho ${ }^{4}$. Também foram encontradas evidências de que há uma relação inversa entre a probabilidade de a firma ser exportadora e a proporção de trabalhadores qualificados/não qualificados empregados na indústria em que a firma atua.

João De Negri (2003) realizou estudos utilizando dados por firmas e encontrou evidências de que o tamanho do mercado brasileiro permite que aquelas instaladas no território nacional atinjam escalas de produção competitivas. Desta forma, as brasileiras também são competitivas na produção de bens em que rendimentos crescentes de escala são um dos fatores determinantes da competitividade das firmas no mercado internacional. Fernanda De Negri (2003) detectou que existem diferenças significativas no desempenho comercial entre empresas nacionais e estrangeiras. Estas últimas possuem, em média, volumes de importação e de exportação superiores aos das empresas nacionais. Entretanto, a magnitude da diferença entre nacionais e estrangeiras é substancialmente maior nas importações do que nas exportações. O estudo mostra que, por um lado, as empresas estrangeiras exportam, em média, $70 \%$ a mais do que as nacionais; e, por outro, importam $290 \%$ a mais.

Há um consenso na literatura de que a internacionalização ${ }^{5}$ das firmas afeta o seu desempenho exportador. Iglesias e Motta Veiga (2002) ressaltaram que há um alto grau de insatisfação quanto à internacionalização das firmas industriais brasileiras. Os estudos que tratam do assunto, contudo, também não são numerosos.

Brasil et alii (1996) estudaram 150 empresas e encontraram evidências de que a necessidade de estar próximo ao cliente, conquistar novos mercados e acesso à tecnologia foram os três primeiros fatores relevantes na decisão das firmas investirem no exterior. O Banco Nacional de Desenvolvimento Econômico e Social - BNDES (1993) realizou um estudo com trinta grandes grupos econômicos nacionais e concluiu que a maioria das filiais das firmas brasileiras no exterior atende à finalidade de aproximar a firma da realidade cultural e organizacional do país receptor e permite que a firma brasileira obtenha ativos específicos capazes de ampliar sua atuação no mercado.

O trabalho de Iglesias e Motta Veiga (2002) torna-se singular no contexto dos estudos sobre internacionalização das firmas porque estabelece 
a ligação entre internacionalização e desempenho exportador. Esses autores selecionaram um conjunto de exportadores com investimento no exterior e encontraram que cerca de $85 \%$ das unidades dessas firmas no exterior são utilizadas em atividades de comércio e distribuição de produtos. Os investimentos produtivos, que representaram $12 \%$ da amostra, estavam concentrados nos setores têxtil, químico, metalurgia básica e autopeças. Segundo os autores, a logística e a necessidade de acompanhar as tendências do mercado consumidor foram os principais motivadores das firmas para promoção de investimentos no exterior.

Em síntese, as evidências empíricas sobre os determinantes das exportações brasileiras mostraram que o Brasil tem vantagens comparativas estáticas nos produtos intensivos em mão-de-obra pouco qualificada e recursos naturais. Há evidências, entretanto, de padrões de comércio intra-industrial e intrafirma entre o Brasil e as principais economias industrializadas. Estudos por firmas indicam também que o seu tamanho e os rendimentos crescentes de escala são variáveis especialmente relevantes na determinação da probabilidade de a firma brasileira tornar-se exportadora. Com relação às evidências sobre internacionalização das firmas brasileiras, os estudos mostraram que algumas delas realizam internacionalização de diversas naturezas. Esse movimento tem sido mais evidente nas indústrias intensivas em mão-de-obra e recursos naturais, indústrias em que o Brasil tem reconhecidamente vantagens comparativas.

Apesar de haver trabalhos que tratam dos determinantes das exportações brasileiras e da internacionalização das firmas, há ainda lacunas na literatura brasileira. Uma delas, especialmente relevante, diz respeito à relação entre um tipo particular de internacionalização, a internacionalização com foco na inovação tecnológica, e sua influência sobre o desempenho exportador da indústria brasileira. Este artigo procura levantar elementos que ajudam a preencher essa lacuna.

\section{INTERNACIONALIZAÇÃO COM FOCO NA INOVAÇÃO TECNOLÓGICA DAS FIRMAS INDUSTRIAIS BRASILEIRAS}

\section{Características das Firmas Brasileiras Internacionalizadas com Foco na Inovação Tecnológica}

Para classificar as firmas industriais em categorias e identificar aquelas que se internacionalizaram com o objetivo de realizar ino- 
vações tecnológicas, este trabalho utilizou informações provenientes da PIA do IBGE, da RAIS do MTE, SECEX do MDIC, e da PINTEC do IBGE.

Utilizou-se a PINTEC para a categorização das firmas e obtenção de outras informações sobre inovação tecnológica. As informações sobre as características da mão-de-obra ocupada nas firmas são provenientes da RAIS. As informações sobre as firmas, como faturamento, valor adicionado e outras, provêm da PIA. Sobre comércio exterior, exportações e importações, a base utilizada é a da SECEX. O ano de referência é 2000.

Para classificação das firmas, foram utilizados dois critérios: i) origem do capital controlador e ii) internacionalização com foco na inovação tecnológica. No questionário da PINTEC/ $/ \mathrm{BGE}^{6}$, há duas perguntas sobre esses critérios. A primeira diz respeito à origem do capital controlador da firma. Neste caso, há três alternativas de resposta: nacional, estrangeiro ou nacional e estrangeiro (misto). A segunda é sobre a localização de outra empresa do grupo utilizada como fonte principal de informação para inovação. Neste caso, há três alternativas disponíveis: a localização de uma outra firma do grupo no exterior; a localização no Brasil de outra firma utilizada como fonte principal de informação para inovação; ou a inexistência, no Brasil e no exterior, de uma outra firma do grupo utilizada como fonte de informação para o processo de inovação, o que implicaria que o esforço e a capacidade de inovação da firma dependeria dela mesma e não de outra firma do grupo. De acordo com as respostas dos entrevistados, foram construídas sete categorias de firmas: três foram consideradas internacionalizadas com foco na inovação e quatro não internacionalizadas com foco na inovação, conforme mostra a Tabela 1.

Neste trabalho, entende-se que uma firma brasileira está internacionalizada com foco na inovação quando está produzindo no Brasil e possui no exterior outra do grupo utilizada como fonte principal de informação para realizar inovação tecnológica. De acordo com esse conceito, as categorias EST_BR, NAC_EXT e EST_EXT são formadas por firmas que realizaram processos de internacionalização com foco na inovação. Na categoria EST_BR, estão as estrangeiras que utilizam firmas localizadas no Brasil como fonte principal de informação para inova- 


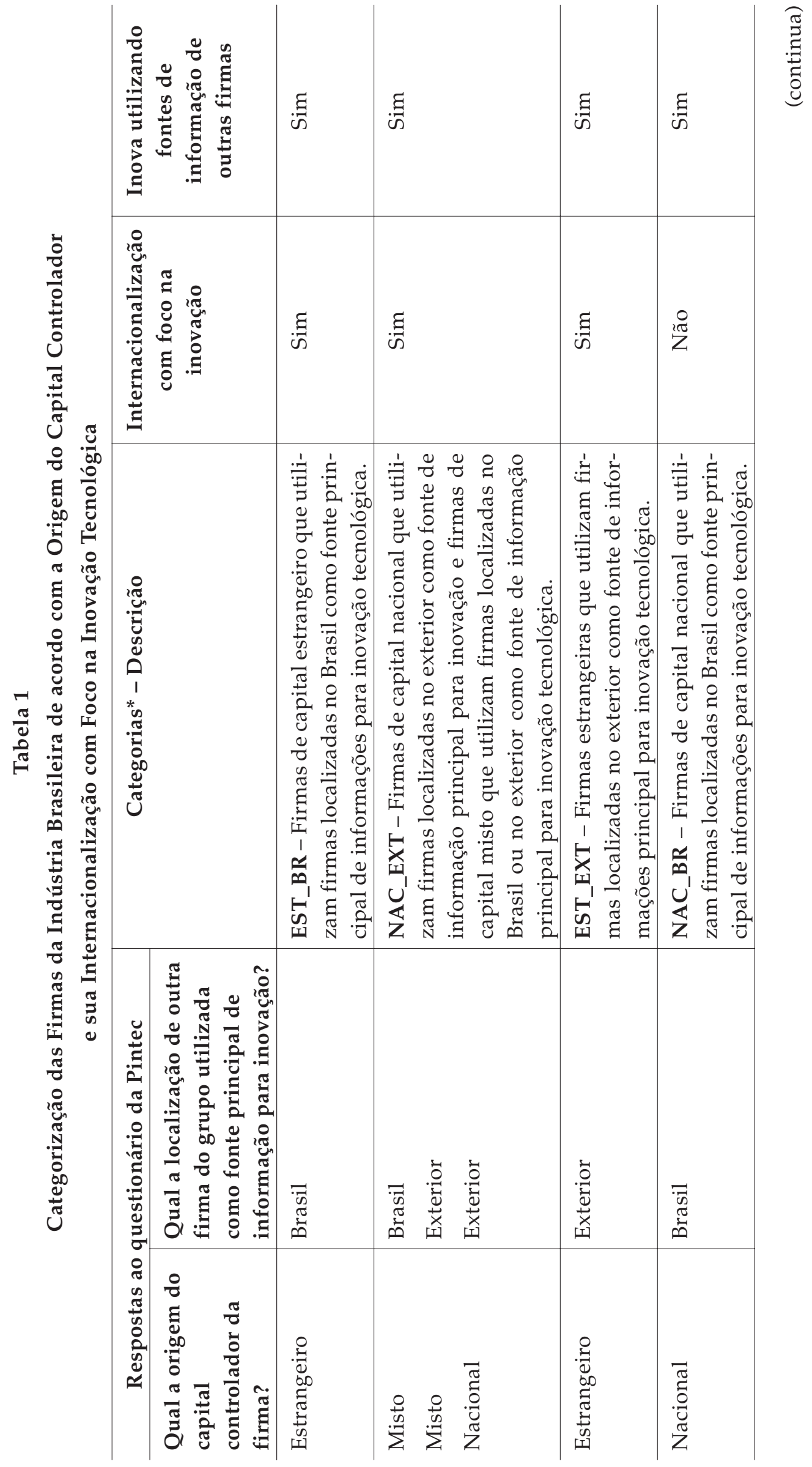


O Impacto da Internacionalização com Foco na Inovação Tecnológica...

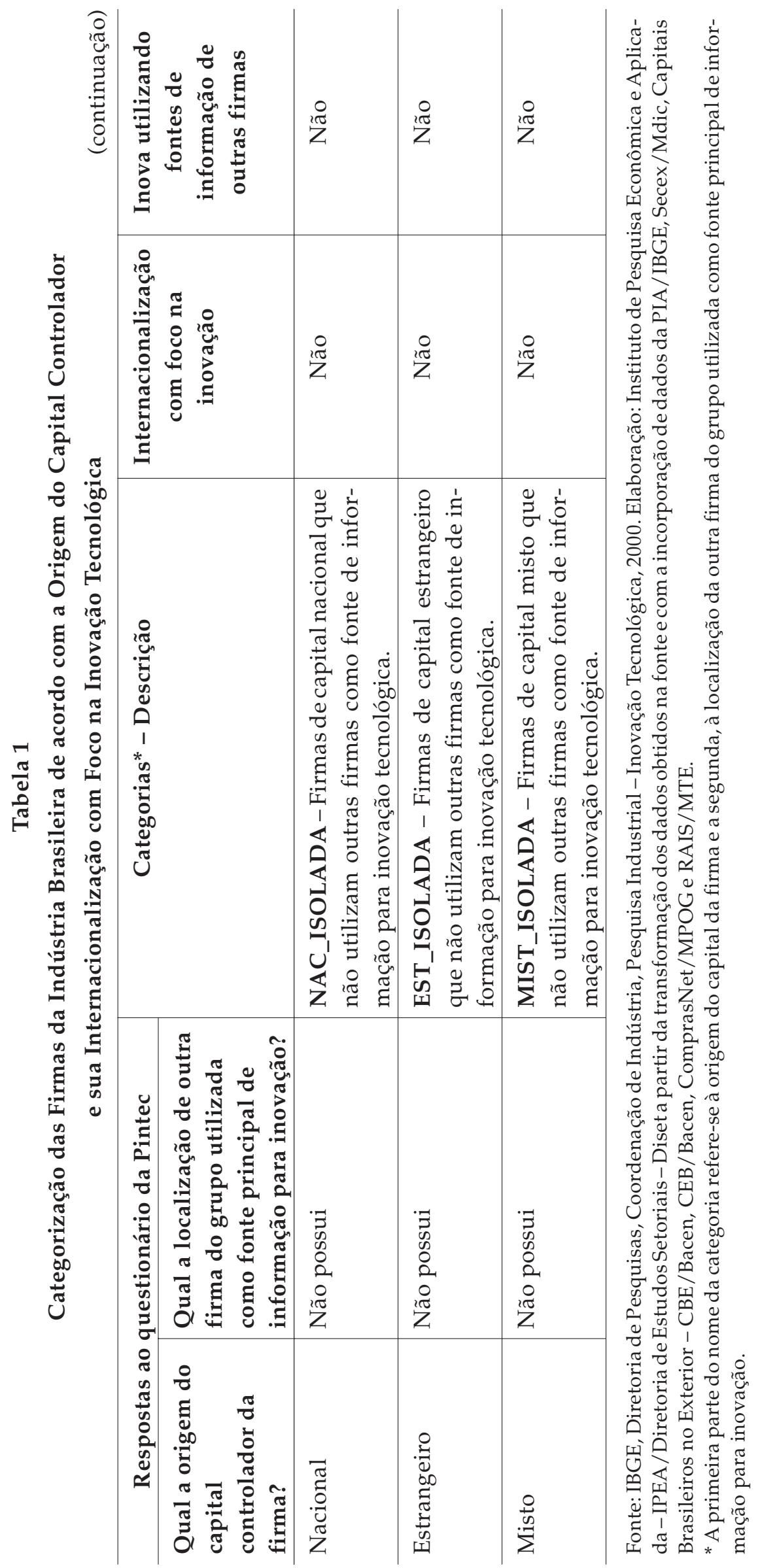


ção. Em virtude de estas serem estrangeiras, é plausível acreditar que, apesar da principal fonte de informação para inovação ser uma firma localizada no Brasil, a sua localização em outros países seria também uma fonte de informações para inovação, o que daria a essa categoria a característica de estar internacionalizada com foco na inovação. A categoria EST_EXT também é formada por firmas de capital controlador estrangeiro. A diferença é que, nesta categoria, elas declararam que a principal fonte de informações para a inovação é uma firma localizada no exterior. A categoria NAC_EXT é formada por firmas de capital misto que utilizam outra firma no exterior ou no Brasil como fonte principal de informação para inovação tecnológica e firmas de capital controlador nacional que possuem no exterior outra firma do grupo utilizada como fonte principal de informação para inovação tecnológica. As firmas de capital misto que utilizam como fonte principal de informação firmas localizadas no Brasil foram consideradas internacionalizadas com foco na inovação, porque muito provavelmente a associação com o capital estrangeiro deve ser também uma das fontes de informação da mesma, apesar de a fonte principal estar localizada no Brasil.

As categorias NAC_BR, NAC_ISOLADA, EST_ISOLADA e MIST_ISOLADA foram consideradas não internacionalizadas com foco na inovação. Na categoria NAC_BR, as firmas de capital nacional têm como fonte principal de informação para inovação tecnológica outras firmas localizadas no Brasil. Como não há capital estrangeiro associado a elas, as mesmas foram consideradas não internacionalizadas. A categoria NAC_ISOLADA é formada por firmas de capital nacional que não declararam possuir outra firma utilizada como fonte para inovação. Nas categorias EST_ISOLADA e MIST_ISOLADA, a presença de capital estrangeiro ou misto indica firmas internacionalizadas; no entanto, estas declararam não possuir outra firma do grupo no Brasil ou no exterior utilizada com o objetivo de obter informação para inovação tecnológica, o que exclui destas categorias a característica de internacionalização com foco na inovação tecnológica.

A Tabela 2 mostra a participação de cada uma dessas categorias na indústria brasileira, considerando as seguintes variáveis: número de firmas, pessoal ocupado, faturamento, valor adicionado, exportação e importação. 
O Impacto da Internacionalização com Foco na Inovação Tecnológica...

Tabela 2

Participação Percentual das Categorias de Firmas na Indústria em Variáveis

Selecionadas para o Ano 2000

\begin{tabular}{l|c|c|c|c|c|c}
\hline \multicolumn{1}{c|}{ Categorias } & $\begin{array}{c}\text { Número } \\
\text { de Firmas }\end{array}$ & $\begin{array}{c}\text { Pessoal } \\
\text { Ocupado }\end{array}$ & $\begin{array}{c}\text { Fatura- } \\
\text { mento }\end{array}$ & $\begin{array}{c}\text { Valor Adi- } \\
\text { cionado }\end{array}$ & $\begin{array}{c}\text { Exporta- } \\
\text { ção }\end{array}$ & $\begin{array}{c}\text { Importa- } \\
\text { ção }\end{array}$ \\
\hline EST_BR & 0,08 & 1,72 & 2,77 & 2,40 & 2,92 & 2,37 \\
NAC_EXT & 0,35 & 1,63 & 3,01 & 2,98 & 5,81 & 2,87 \\
EST_EXT & 1,33 & 12,26 & 25,33 & 23,41 & 27,32 & 35,94 \\
NAC_BR & 0,73 & 8,39 & 15,95 & 21,44 & 14,75 & 29,46 \\
NAC_ISOLADA & 96,10 & 70,85 & 45,54 & 42,79 & 39,15 & 21,17 \\
EST_ISOLADA & 1,16 & 4,18 & 5,74 & 5,39 & 7,20 & 7,24 \\
MIST_ISOLADA & 0,24 & 0,97 & 1,66 & 1,59 & 2,85 & 0,95 \\
Indústria-Total & 100,0 & 100,0 & 100,0 & 100,0 & 100,0 & 100,0 \\
\hline
\end{tabular}

Fonte: IBGE, Diretoria de Pesquisas, Coordenação de Indústria, Pesquisa Industrial - Inovação Tecnológica, 2000. Elaboração: IPEA/Diset a partir da transformação dos dados obtidos na fonte e com a incorporação de dados da PIA/IBGE, Secex/Mdic, CBE/Bacen, CEB/Bacen, ComprasNet/MPOGe RAIS/MTE.

Conforme pode ser observado nos indicadores apresentados na Tabela 2, 96,10\% das firmas estão classificadas na categoria NAC_ISOLADA. Apesar de numericamente esta categoria representar a grande maioria delas, sua representatividade cai de forma significativa quando se considera sua participação no valor adicionado da indústria: elas contribuem com menos da metade deste valor, 42,79\%. A participação desse segmento nas exportações é ainda menor, $39,15 \%$.

Dentre as categorias internacionalizadas com foco na inovação, destaca-se a NAC_EXT. A origem do capital controlador da firma é nacional ou compartilhado com capital estrangeiro. Esta representa apenas $0,35 \%$ das firmas na indústria brasileira. Sua baixa representatividade em termos numéricos é esperada porque o processo de internacionalização daquelas com foco na inovação não é um fenômeno generalizado na economia brasileira. Apesar de poucas firmas de capital nacional ou misto realizarem esse tipo de internacionalização, é importante ressaltar que a representatividade desse grupo aumenta quase nove vezes quando a variável de análise é o faturamento ou o valor adicionado na indústria, e quase dezessete vezes quando se observa a variável exportação. Tais firmas são responsáveis por aproximadamente 3\% do faturamento e do valor adicionado da indústria, e por $5,8 \%$ do total exportado, o que significa que exportam anualmente mais de US\$2,5 bilhões. 
Quais as principais diferenças entre essas categorias de firmas? Existem diferenças entre elas quando se considera a média por categoria de variáveis como tamanho delas, valor adicionado, exportações, importações e características da mão-de-obra? Para responder a estas perguntas, a Tabela 3 apresenta a média de características da firma e dos trabalhadores dentro de cada uma das categorias criadas a partir do critério de capital controlador e internacionalização com foco na inovação.

Quando são comparadas as categorias dessas, a primeira evidência especialmente relevante é que a menor escala média de produção, mensurada por meio do pessoal ocupado, do faturamento ou do valor adicionado, é encontrada na categoria NAC_ISOLADA. A média do pessoal ocupado nas firmas desta categoria, no ano 2000, foi de 102,8, e o faturamento médio nesse mesmo ano foi de $R \$ 4,1$ milhões. $O$ valor adicionado médio nessa categoria também é baixo quando comparado com as demais. Para quaisquer destas variáveis, a dispersão em torno da média é relativamente alta indicando que essa categoria é mais heterogênea que as demais. Essas firmas formam a grande maioria numérica das industriais brasileiras. Na maioria dos casos, é plausível acreditar que, na média, elas possivelmente operam com menor eficiência de escala e são pouco integradas ao comércio internacional, mas que, em conjunto, alcançam 39,15\% do total das exportações industriais. Essas firmas, além de não serem internacionalizadas com foco na inovação, são também pouco internacionalizadas via comércio exterior, uma vez que exportam em média US $\$ 0,3$ milhão e importam em média US $\$ 0,1$ milhão, muito abaixo das demais categorias. É importante destacar, entretanto, que essas têm em média cem pessoas ocupadas, faturamento de $\mathrm{R} \$ 4$ milhões e que exportam US\$300 mil. Isso significa uma relação exportação/faturamento próxima das demais categorias. Levando-se em conta que essa relação representa a importância da exportação na atividade produtiva da firma, na média o indicador parece mostrar que as exportações, nessa categoria, têm importância relativa similar às das demais.

A segunda evidência relevante é que há semelhança quanto à escala de produção entre as das categorias NAC_ISOLADA, EST_ISOLADA e MIST_ISOLADA; no entanto, há diferenças entre estas categorias quando se verifica o desempenho comercial. Essas se assemelham en- 
O Impacto da Internacionalização com Foco na Inovação Tecnológica...

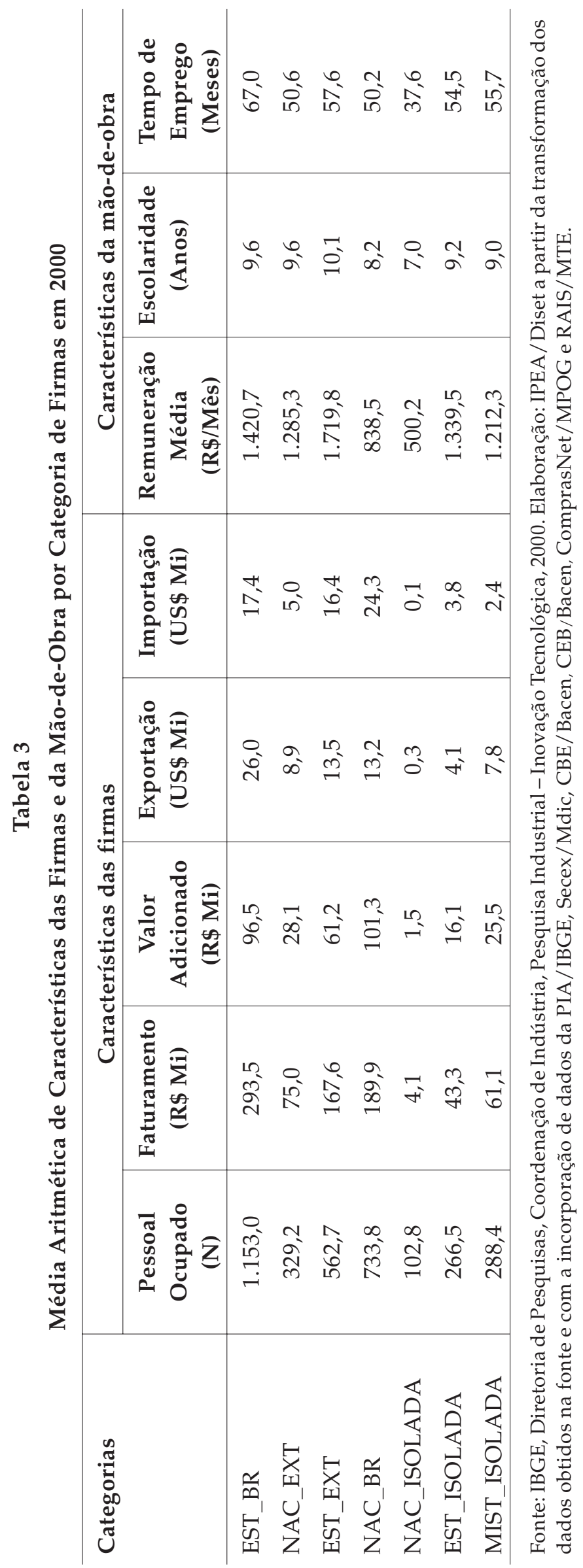


tre si pelo fato de não terem declarado que possuem outra firma no Brasil ou no exterior utilizada como fonte principal de informação para a inovação, e diferem quanto à origem do capital controlador da firma, se nacional, estrangeiro ou misto, respectivamente. É plausível acreditar que as estrangeiras da categoria EST_ISOLADA e as de capital nacional associadas ao capital estrangeiro da categoria MIST_ISOLADA têm maior articulação com canais de comercialização no exterior, o que ampliaria seu potencial exportador e importador médio, independentemente de estarem associadas à iniciativa de buscar em outras firmas informações para inovação tecnológica.

O expressivo saldo comercial negativo da categoria NAC_BRé a terceira evidência que chama a atenção nas estatísticas associadas às características das firmas. Nesta, a origem do capital controlador é nacional e são utilizadas firmas nacionais como fonte principal de informação para a inovação. O motivo desse saldo negativo está possivelmente vinculado ao fato de que há um grande número dessas firmas na indústria química, montagem de veículos, autopeças e bens de capital. Estes segmentos são reconhecidamente setores nos quais as importações ocorrem com maior intensidade do que em outros segmentos da indústria $^{7}$. Portanto, é plausível acreditar que as inovações de processo desses segmentos demandem maior intensidade de importações de máquinas e equipamentos.

A quarta evidência está relacionada ao fato de a escala de produção ser relativamente maior nas categorias consideradas internacionalizadas com foco na inovação. Na categoria EST_BR, destaca-se o fato de as empresas, em média, empregarem um grande número de pessoas. Essa estatística é razoável porque na categoria EST_BR há grandes empresas de capital controlador estrangeiro no segmento de alimentação, o qual é intensivo em mão-de-obra. Isto explica também o expressivo saldo comercial dessa categoria, pois, dadas as vantagens comparativas da indústria brasileira, as exportações de produtos como óleo de soja, suco de laranja, café solúvel e outros acabam por gerar superávits comerciais expressivos.

Quanto às características individuais dos trabalhadores, é possível observar que aquelas internacionalizadas com foco na inovação (EST_BR, NAC_EXT, EST_EXT) e as não internacionalizadas com o 
mesmo foco, mas com a presença de capital estrangeiro (EST_ISOLADA e MIST_ISOLADA) remuneram melhor a mão-de-obra do que as de capital nacional não internacionalizadas com o objetivo de inovar (NAC_BR e NAC_ISOLADA). A maior parte do diferencial de salários deve estar relacionada com a maior produtividade da mãode-obra, que, por sua vez, depende das especificidades das firmas e das características individuais dos trabalhadores.

Primeiro, quanto à parcela da remuneração associada às características da mão-de-obra, as estatísticas apresentadas mostram que a escolaridade média do trabalhador e o tempo de permanência médio do mesmo na firma são menores nas categorias NAC_BR e NAC_ISOLADA. Estas duas variáveis têm uma relação direta com a tecnologia utilizada pela firma. $\mathrm{O}$ tempo de permanência do trabalhador na firma é um indicador importante de aprendizado tecnológico e a escolaridade média dos trabalhadores nela é uma proxy para o nível tecnológico da firma, pois é razoável supor que tecnologias mais sofisticadas demandem mão-de-obra mais qualificada. A internacionalização com foco na inovação, que caracteriza as firmas das categorias EST_BR, NAC_EXT e EST_EXT, deve exigir trabalhadores mais escolarizados e mais bem treinados. Os trabalhadores brasileiros devem passar por algum processo de aprendizado no interior da firma. Muitas vezes o treinamento está associado à exigência de escolaridade concluída ou em curso no supletivo, por exemplo, o que impulsiona de alguma maneira a qualificação da mão-de-obra doméstica. É razoável acreditar que esse processo de aprendizado se reflita no tempo de permanência do trabalhador nas firmas, pois elas têm dispêndios de treinamento que seriam perdidos com uma rotatividade alta. Emprego mais estável favorece o aprendizado e reduz os dispêndios de treinamento, atração e demissão de pessoal. No caso das categorias EST_ISOLADA e MIST_ISOLADA, muito provavelmente o diferencial positivo de remuneração estaria associado à presença de capital estrangeiro ${ }^{8}$.

Em segundo lugar, quanto à parcela de remuneração do trabalhador associada às características das firmas, é possível que as das categorias EST_BR, NAC_EXT, EST_EXT, EST_ISOLADA e MIST_ISOLADA tenham uma preocupação maior com a competitividade e, assim, possam fazer uso de mecanismos de salário eficiência para aumentar a produtividade da sua mão-de-obra. A teoria do salário de eficiência 
baseia-se na hipótese de que o custo de monitoramento pode ser muito elevado nas firmas maiores e/ou nas que operam com tecnologias mais sofisticadas, e de que a rotatividade e o treinamento são custosos para a firma. A escala de produção também pode ser um motivador da remuneração maior nessas categorias, pois os rendimentos crescentes de escala podem garantir maior produtividade para firmas maiores. É importante ressaltar ainda que a exposição da firma ao mercado internacional, via internacionalização com foco na inovação ou via presença de capital estrangeiro no controle das firmas, cria externalidades positivas capazes de aumentar a produtividade do trabalho.

Em síntese, foi possível observar, pelas características das firmas e da força de trabalho, que as internacionalizadas com foco na inovação são maiores, possivelmente aproveitam de forma mais eficiente os rendimentos crescentes de escala e se inserem no comércio internacional de forma mais intensa, pois exportam e importam mais do que as outras categorias de firmas. Além dessas características, foi possível ver que elas remuneram melhor a mão-de-obra, porque muito provavelmente são mais produtivas, empregam pessoal com maior escolaridade e possivelmente fazem algum tipo de treinamento para o seu pessoal ocupado. Dentre as que realizaram processos de internacionalização com foco na inovação tecnológica, cabe destacar com especial relevância as da categoria NAC_EXT. Nela, encontram-se firmas de capital nacional e misto as quais podem ser tomadas como exemplos de internacionalização a serem seguidos por outras de capital nacional, principalmente aquelas que já fazem um esforço inovador dentro de um grupo empresarial, como as da categoria NAC_BR.

\section{IMPORTÂNCIA RELATIVA DOS TIPOS DE GASTOS EM ATIVIDADES VOLTADAS PARA INOVAÇÃO TECNOLÓGICA}

Na seção anterior, vimos que as categorias de firmas aqui em análise diferem entre si quanto às características das firmas e da mão-de-obra. Esse diferencial seria importante para alavancar as inovações das firmas? Qual o percentual de firmas inovadoras em cada uma das categorias de firma? Para responder a esta pergunta, a Tabela 4 apresenta o percentual de firmas que realizam inovações tecnológicas, de produto e de processo, em cada uma das categorias. 
O Impacto da Internacionalização com Foco na Inovação Tecnológica...

Tabela 4

Percentual das Firmas que Realizaram Inovação Tecnológica por Categoria de Firmas entre 1998-2000

\begin{tabular}{l|c|c|c}
\hline Categorias & Inovadoras & $\begin{array}{c}\text { Inovadoras de } \\
\text { Produto }\end{array}$ & $\begin{array}{c}\text { Inovadoras de } \\
\text { Processo }\end{array}$ \\
\hline EST_BR & 94,0 & 68,4 & 75,8 \\
NAC_EXT & 75,5 & 64,1 & 55,0 \\
EST_EXT & 95,9 & 79,9 & 74,4 \\
NAC_BR & 93,7 & 72,0 & 77,4 \\
NAC_ISOLADA & 30,0 & 16,1 & 24,1 \\
EST_ISOLADA & 23,5 & 15,3 & 18,0 \\
MIST_ISOLADA & 38,1 & 34,7 & 29,3 \\
\hline
\end{tabular}

Fonte: IBGE, Diretoria de Pesquisas, Coordenação de Indústria, Pesquisa Industrial - Inovação Tecnológica, 2000. Elaboração: IPEA/Diset a partir da transformação dos dados obtidos na fonte e com a incorporação de dados da PIA/IBGE, Secex/Mdic, CBE / Bacen, CEB / Bacen, ComprasNet/MPOGe RAIS/MTE.

Obs.: As colunas e as linhas não somam $100 \%$ porque o percentual diz respeito apenas às empresas que realizaram algum tipo de inovação em cada categoria. Desta forma, na primeira linha, primeira coluna, o número 94,0 significa que $94 \%$ das firmas da categoria EST_BR realizaram inovação tecnológica no período 1998-2000. O restante, 6\%, não teria realizado inovação tecnológica.

As estatísticas apresentadas na Tabela 4 mostram que as categorias que possuem outra empresa do grupo utilizada como fonte principal de informação para inovação têm maior percentual de firmas inovadoras do que aquelas que não declararam utilizar outras firmas como fonte principal de informação. Esse comportamento é também verificado no caso das inovações de processo e de produto. Quais são os gastos mais importantes que as firmas devem realizar para aumentar a probabilidade de ser uma inovadora?

Uma medida objetiva para identificar qual a importância que a firma atribui à implementação de inovações é o valor dos dispêndios das firmas em atividades vinculadas à inovação tecnológica como proporção do seu faturamento. A Tabela 5 apresenta a média do percentual de gastos das firmas em relação ao seu faturamento, para seis tipos de atividades voltadas à inovação tecnológica, por categoria de firmas. $\mathrm{O}$ primeiro tipo de gasto compreende o realizado nas atividades internas de Pesquisa e Desenvolvimento - P\&D. Neste tipo de gasto, englobam-se o desenho, a construção e o teste de protótipos e de instalações-piloto, bem como o desenvolvimento de softwares. A aquisição externa de $\mathrm{P} \& \mathrm{D}$ diz respeito à contratação de serviços de empresas ou instituições tecnológicas. Nas aquisições de outros conhecimentos ex- 
ternos, estão incluídos acordos de transferência originados da compra de licença e direitos de exploração de patentes e uso de marcas, know-how, software e outros tipos de conhecimento de terceiros. Para introdução de inovações tecnológicas no mercado, a firma realiza gastos em comercialização, testes de mercado e publicidade para o lançamento, além da adaptação do produto a diferentes mercados. No caso de projeto industrial, ela realiza dispêndios que incluem novas especificações técnicas, características operacionais, métodos, padrões de trabalho e softwares, além de atividades de metrologia, normalização e avaliação de conformidade. Para treinamento da mão-de-obra, além dos gastos diretos, são também contemplados os gastos com a aquisição de serviços de técnicos especializados 9 .

Tabela 5

Média do Dispêndio das Firmas em Atividades Relativas à Inovação Tecnológica como Proporção Percentual do Faturamento, por Categorias de Firmas, em 2000

\begin{tabular}{l|c|c|c|c|c|c}
\hline Categorias & $\begin{array}{c}\text { Gastos } \\
\text { em P\&D }\end{array}$ & $\begin{array}{c}\text { Aquisição } \\
\text { de P\&D }\end{array}$ & $\begin{array}{c}\text { Aquisi- } \\
\text { ção de } \\
\text { conheci- } \\
\text { mentos }\end{array}$ & $\begin{array}{c}\text { Treinamento } \\
\text { da } \\
\text { mão-de-obra }\end{array}$ & $\begin{array}{c}\text { Introdução } \\
\text { das } \\
\text { inovações } \\
\text { no mercado }\end{array}$ & $\begin{array}{c}\text { Projeto } \\
\text { indús- } \\
\text { tria }\end{array}$ \\
\hline EST_BR & 0,73 & 0,20 & 0,10 & 0,06 & 0,14 & 0,99 \\
NAC_EXT & 0,26 & 0,06 & 0,06 & 0,23 & 0,61 & 0,88 \\
EST_EXT & 0,89 & 0,23 & 2,20 & 3,07 & 0,57 & 0,10 \\
NAC_BR & 1,90 & 0,15 & 0,76 & 0,39 & 0,56 & 0,85 \\
NAC_ISOLADA & 0,73 & 0,10 & 0,16 & 0,17 & 0,23 & 0,71 \\
EST_ISOLADA & 0,29 & 0,01 & 0,02 & 0,02 & 0,09 & 0,09 \\
MIST_ISOLADA & 1,00 & 0,02 & 0,01 & 0,02 & 0,09 & 0,11 \\
Indústria-total & 0,75 & 0,10 & 0,27 & 0,52 & 0,25 & 0,67 \\
\hline
\end{tabular}

Fonte: IBGE, Diretoria de Pesquisas, Coordenação de Indústria, Pesquisa Industrial - Inovação Tecnológica, 2000. Elaboração: IPEA/Diset a partir da transformação dos dados obtidos na fonte e com a incorporação de dados da PIA/IBGE, Secex/Mdic, CBE/Bacen, CEB/Bacen, ComprasNet/MPOG e RAIS/MTE.

Os dados da Tabela 5 mostram que, para o agregado da indústria brasileira, as atividades de inovação mais dispendiosas das firmas são os gastos em P\&D, treinamento da mão-de-obra e projeto industrial. Os gastos em treinamento da mão-de-obra são elevados muito provavelmente porque a maior parte das inovações de processo é realizada com a introdução de novas máquinas e equipamentos que necessitam de treinamento específico da mão-de-obra para sua operação. 
Em princípio, parece não haver um padrão específico que possa distinguir as categorias de firmas. No entanto, é possível observar que, na média industrial, as aquisições de conhecimento e P\&D fora da firma são relativamente baixas, mas, nas categorias EST_BR e EST_EXT, em que o capital controlador é de origem estrangeira, tais aquisições parecem ser relativamente maiores. Apesar de não existirem informações detalhadas sobre a origem delas, pode ser razoável acreditar que uma parcela importante dessas aquisições ocorra fora do país.

O dispêndio de $\mathrm{P} \& \mathrm{D}$ proporcionalmente ao faturamento das empresas de capital nacional que utilizam outros estabelecimentos no Brasil como fonte de informação principal para a inovação tecnológica (NAC_BR) é em média o maior entre todas as categorias - inclusive comparativamente às empresas internacionalizadas com foco na inovação. Esse comportamento pode indicar que as firmas de capital controlador nacional, que utilizam como fonte principal de informação para inovação tecnológica outra firma do grupo localizada no Brasil, devem empenhar-se mais em gerar inovações tecnológicas com seu próprio P\&D do que aquelas das categorias em que o capital controlador é estrangeiro, ou seja, o esforço endógeno é maior. Essas evidências são corroboradas também pelos indicadores de gastos em $P \& D$ realizados pelas firmas de capital controlador misto, categoria MIST_ISOLADA, que são relativamente altos quando comparados com os das demais categorias. Isso mostra que a localização dos gastos em P\&D guarda íntima relação com a origem do capital, tendendo a se concentrar em matrizes. Essa conclusão vai ao encontro de pesquisas anteriormente elaboradas ${ }^{10}$.

Dado que inovação é um aspecto central da competitividade empresarial, faz-se necessário desenvolver estudos específicos para essa categoria, inclusive abordando as questões de internacionalização. Seria importante compreender se há um conjunto significativo de empresas NAC_BR internacionalizadas, ainda que não com foco na inovação. Isso significaria que o esforço endógeno (nacional) de inovação estaria dando frutos na competitividade internacional. O problema que esse tipo de empresa apresenta é o seu saldo médio negativo de comércio exterior, o que sugere dependência, e não autonomia tecnológica. Responder a essas perguntas exigiria outras bases de dados referentes a investimentos no exterior. 
Destacam-se também os indicadores que mostram pouca importância dada aos gastos com introdução das inovações no mercado das categorias EST_ISOLADA e MIST_ISOLADA. Nestas, o percentual de firmas inovadoras é menor do que nas demais, conforme mostrou a análise da Tabela 4, o que torna o resultado trivial. Menos triviais, entretanto, são os indicadores da categoria NAC_ISOLADA, uma vez que nela os gastos com a introdução de inovações no mercado são relativamente maiores, quando comparados com os das categorias EST_ISOLADA e MIST_ISOLADA. Também são relativamente grandes os gastos realizados em P\&D e projetos industriais. Isso parece indicar que muitos projetos industriais e gastos em P\&D da categoria NAC_ISOLADA não chegam a consolidar-se em inovações validadas pelo mercado, o que sugere que a inovação é mais de processo, voltada para a racionalização da produção (custos, qualidade etc.), em vez de buscar novos nichos de mercados.

Na categoria NAC_EXT, a relação gastos / faturamento nos itens gastos em $\mathrm{P} \& \mathrm{D}$, aquisição de $\mathrm{P} \& \mathrm{D}$, aquisição de conhecimento e treinamento da mão-de-obra é relativamente menor do que na média da indústria. Parte desse diferencial pode ser creditado ao fato de o faturamento médio dessa categoria ser maior do que a média industrial. As firmas da mesma podem também estar utilizando suas bases no exterior para imitar inovações tecnológicas disponíveis em outros mercados, ou, então, estar realizando parte dos seus gastos em atividades voltadas para inovação tecnológica nas outras firmas do grupo localizadas no exterior. Independentemente da razão pela qual as firmas dessa categoria gastam relativamente menos do que a média em algumas atividades de inovação, é importante ressaltar que poderia haver espaço para mecanismos que incentivem o aumento de gastos nessas atividades.

Os dispêndios realizados pelas firmas em atividades voltadas à inovação não refletem, entretanto, a importância dos gastos de cada categoria no total de dispêndios que a indústria brasileira realiza com essas atividades. Para mensurá-la, a Tabela 6 apresenta o valor total dos dispêndios em atividades relativas à inovação realizados no ano 2000, por categoria de firmas.

A Tabela 6 mostra que as atividades de P\&D e projeto industrial correspondem aos principais gastos realizados pelas firmas com o objetivo de inovar. Em 2000, a indústria brasileira gastou $\mathrm{R} \$ 3,7$ bilhões em P\&D. Uma parte significativa desses gastos foi realizada por firmas de 
O Impacto da Internacionalização com Foco na Inovação Tecnológica...

Tabela 6

Valor Total dos Dispêndios em Atividades Relativas à Inovação Tecnológica por Categorias de Firmas em 2000 (R\$ Mi)

\begin{tabular}{l|c|c|c|c|c|c}
\hline \multicolumn{1}{c|}{ Categorias } & $\begin{array}{c}\text { Gastos } \\
\text { em P\&D }\end{array}$ & $\begin{array}{c}\text { Aquisi- } \\
\text { ção de } \\
\text { P\&D }\end{array}$ & $\begin{array}{c}\text { Aquisi- } \\
\text { ção de } \\
\text { conheci- } \\
\text { mentos }\end{array}$ & $\begin{array}{c}\text { Treina- } \\
\text { mento da } \\
\text { mão-de- } \\
\text { obra }\end{array}$ & $\begin{array}{c}\text { Introdução } \\
\text { das inov- } \\
\text { ções no } \\
\text { mercado }\end{array}$ & $\begin{array}{c}\text { Projeto } \\
\text { indus- } \\
\text { trial }\end{array}$ \\
\hline EST_BR & 164 & 33 & 38 & 4 & 44 & 193 \\
NAC_EXT & 40 & 11 & 34 & 19 & 47 & 50 \\
EST_EXT & 1.403 & 329 & 680 & 143 & 693 & 1.412 \\
NAC_BR & 734 & 93 & 79 & 37 & 89 & 239 \\
NAC_ISOLADA & 1.274 & 157 & 316 & 205 & 424 & 1.153 \\
EST_ISOLADA & 95 & 7 & 21 & 7 & 119 & 68 \\
MIST_ISOLADA & 30 & 0,6 & 0,8 & 1,5 & 5 & 183 \\
Indústria-total & 3.740 & 630,6 & $1.168,8$ & 416,5 & 1.421 & 3.298 \\
\hline
\end{tabular}

Fonte: IBGE, Diretoria de Pesquisas, Coordenação de Indústria, Pesquisa Industrial - Inovação Tecnológica, 2000. Elaboração: IPEA/Diset a partir da transformação dos dados obtidos na fonte e com a incorporação de dados da PIA/IBGE, Secex/Mdic, CBE/Bacen, CEB/Bacen, ComprasNet/MPOG e RAIS/MTE.

capital controlador estrangeiro, particularmente as pertencentes à categoria EST_EXT foram responsáveis por gastar R\$ 1,4 bilhões ${ }^{11}$. É importante observar que essas firmas representam apenas 1,33\% do total de firmas da indústria brasileira. As firmas da categoria NAC_ISOLADA, que representam $96 \%$ delas, gastaram cerca de R $\$ 1,3$ bilhões.

Esse padrão se repete para os demais tipos de gastos, ou seja, as firmas de capital controlador estrangeiro da categoria EST_EXT realizam a grande maioria dos gastos em atividades voltadas à inovação, e, como representam uma parcela menor de firmas em relação ao total, os gastos individuais dessas são significativamente superiores quando comparados aos das demais categorias. Da mesma forma, a segunda categoria que mais gasta em valores absolutos é a NAC_ISOLADA, mas, como nesta categoria se encontra a grande maioria das firmas da indústria brasileira, o valor médio investido por elas é o menor dentre as categorias.

Para quantificar a importância dos tipos de dispêndios como proporção do faturamento das firmas na probabilidade de ela ser uma inova- 
dora, foram estimados três modelos probabilísticos em que a variável dependente é a condição de a firma ser ou não inovadora, inovadora de produto e inovadora de processo, e as variáveis explicativas são os diferentes tipos de gastos em atividades voltadas para a inovação tecnológica divididos pelo faturamento. A escolaridade média dos trabalhadores na firma também foi introduzida como variável explicativa. Os resultados são apresentados na Tabela 7. Além dos tipos de gastos, foram também introduzidas variáveis dummies para divisões de acordo com a Classificação Nacional de Atividade Econômica que não foram reportadas na tabela ${ }^{12}$. A variável "gastos com treinamento da mão-de-obra" não foi significativa no modelo em que a variável dependente era a inovação de produto, e as variáveis gastos em P\&D e projeto industrial não foram significativas no modelo de inovação de processo. $\mathrm{O}$ fato de a inovação de produto não estar significativamente correlacionada com treinamento sugere inovações incrementais, que pouco afetam as formas de trabalho. Outras estatísticas do modelo podem ser vistas na tabela em questão.

A probabilidade marginal mostrada na mesma tabela demonstra o quanto aumenta a probabilidade de a firma ser inovadora para cada aumento de uma unidade da variável explicativa. Como os tipos de dispêndios estão relacionados ao faturamento, não é razoável acreditar no aumento de uma unidade nessas variáveis, pois isto significaria investir todo o faturamento da firma em atividades vinculadas à inovação tecnológica. Para melhor interpretar os resultados, foi simulado quanto aumentaria a probabilidade de a firma ser uma inovadora se os dispêndios nas diversas atividades de inovação aumentassem $100 \%$, mantido constante o faturamento das firmas. Os resultados da simulação são apresentados entre colchetes na coluna da probabilidade marginal na Tabela 7.

Os resultados da simulação indicaram que os três dispêndios mais relevantes para aumentar a probabilidade de a firma ser uma inovadora são os realizados em treinamento da mão-de-obra, P\&D e projeto industrial. Uma faixa de gasto $100 \%$ acima dos realizados pelas firmas industriais brasileiras em treinamento da sua mão-de-obra resultaria em um aumento de $12 \%$ na probabilidade de as firmas serem inovadoras. Esse resultado é particularmente relevante, pois significa dizer que um esforço para aumentar a taxa de inovação da indústria brasileira requer maiores investimentos em escolaridade e treinamento, o que poderia ser um dos pilares de um programa nacional pró-inovação. No caso dos gastos em P\&D, o aumento na probabilidade de inovar é de 
O Impacto da Internacionalização com Foco na Inovação Tecnológica...

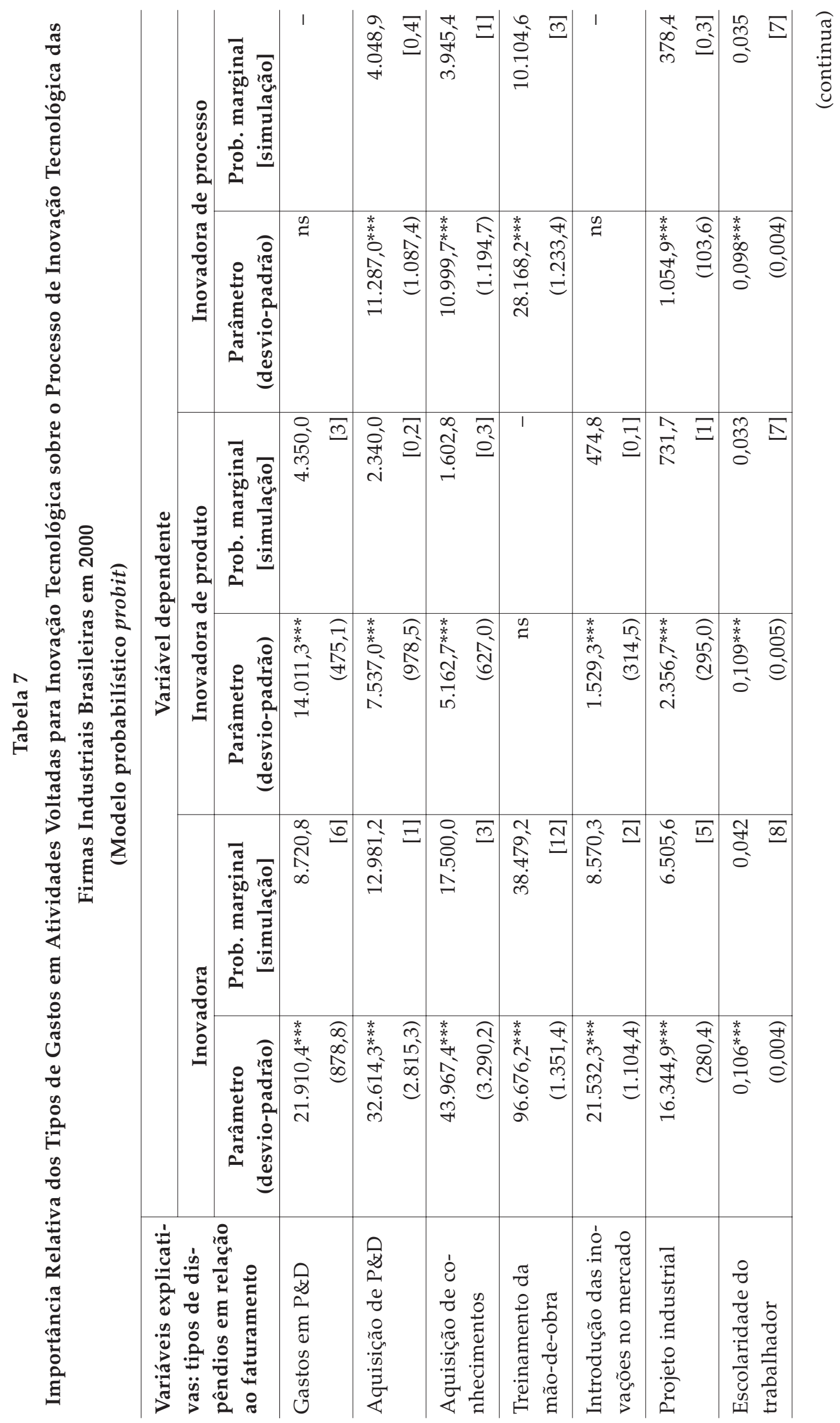




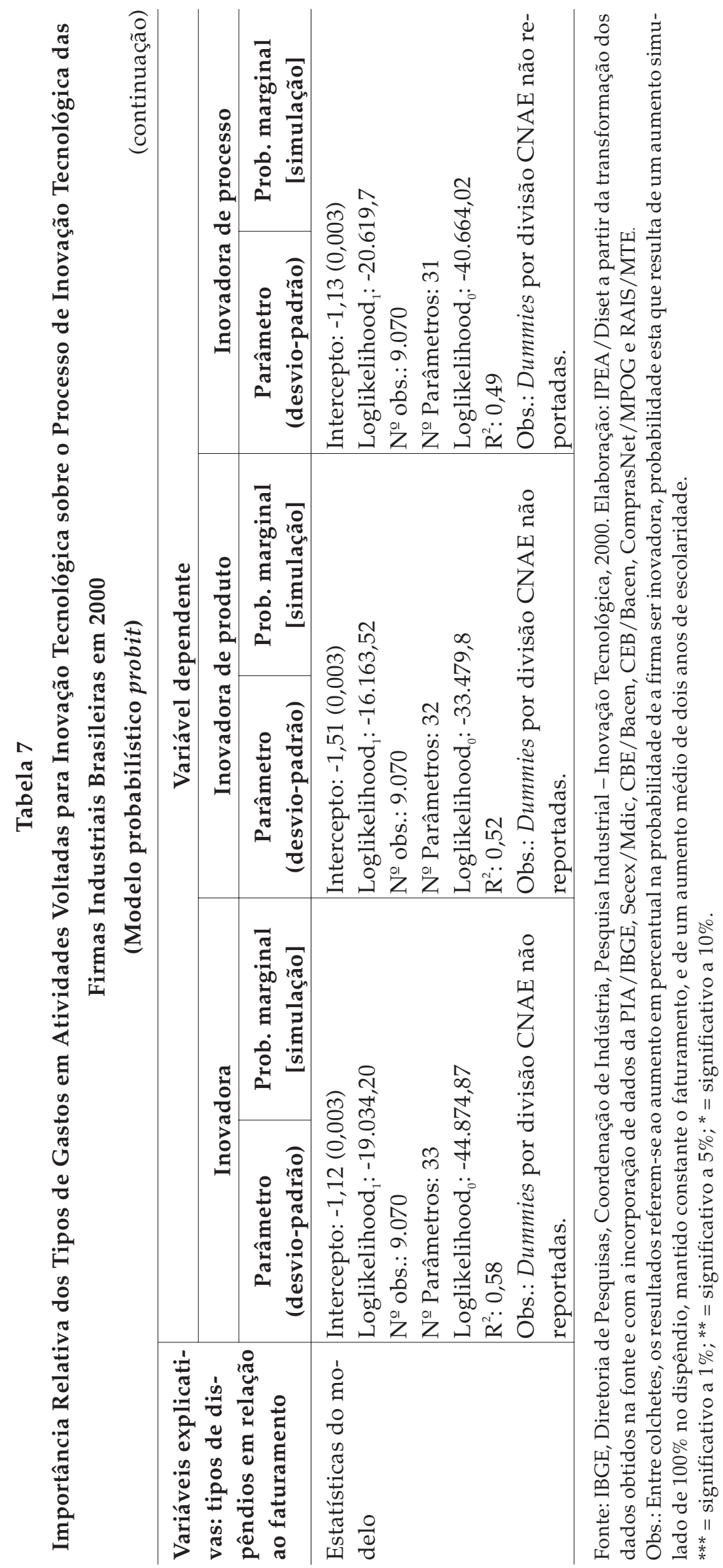


$6 \%$ e, no caso dos gastos em projeto industrial, esse aumento seria de $5 \%$. A probabilidade de a firma ser inovadora aumentaria também $8 \%$ caso a escolaridade média dos trabalhadores nas firmas aumentasse dois anos em média. Cada ponto percentual de aumento na probabilidade de as firmas serem inovadoras significa que 227 novas firmas se tornariam inovadoras na indústria brasileira. Dessa maneira, um aumento de $100 \%$ nos gastos dos três dispêndios mais relevantes do ponto de vista dos determinantes da inovação tecnológica - o que representaria um aumento no valor de $\mathrm{R} \$ 7,4$ bilhões, associado a um aumento de dois anos na escolaridade média dos trabalhadores ocupados nas firmas - significaria um aumento de aproximadamente sete mil novas firmas inovadoras na indústria.

Em princípio, parece ser relativamente alta a relação entre o aumento de $R$ \$ 7,4 bilhões de gastos em treinamento da mão-de-obra, P\&D e projeto industrial e a geração de sete mil novas firmas inovadoras. Esta relação merece melhor qualificação. Segundo dados da Pintec, existem na indústria brasileira 70 mil firmas com mais de dez pessoas ocupadas. Destas, cerca de 22 mil são inovadoras. O aumento de sete mil novas firmas industriais inovadoras significaria ampliar em mais de $30 \%$ o número de firmas que realizam inovações na indústria brasileira. Outro ponto relevante é que a maior parte dos gastos em atividades voltadas para a inovação tecnológica são realizadas por firmas de capital controlador estrangeiro. Firmas de capital nacional ou misto da categoria NAC_EXT possuem maior êxito em alcançar inovações e têm dispêndios muito menores do que a média, conforme observado nas Tabelas 5 e 6. Seria razoável acreditar que um esforço muito menor seria necessário se firmas das categorias NAC_BR e NAC_ISOLADA identificassem o exemplo das da categoria NAC_EXT e realizassem internacionalização com foco na inovação.

Nos modelos desagregados por inovadoras de produto e processo, os parâmetros caíram de forma significativa. Essa queda seria esperada porque a interface entre inovadoras de processo e de produto não é grande. No modelo de inovadora de produto, os gastos mais importantes são aqueles realizados em P\&D, pois um aumento de $100 \%$ nesses gastos resultaria em um aumento de $3 \%$ na probabilidade de a firma ser inovadora. No modelo de inovadora de processo, o gasto mais importante é realizado no treinamento da mão-de-obra. Um aumento de $100 \%$ nesse gasto resultaria em um aumento de $3 \%$ na probabilidade de a firma ser inovadora. $\mathrm{O}$ aumento de dois anos na escolaridade média 
do trabalhador teria o mesmo impacto tanto no modelo de inovadora de produto quanto no de processo, ou seja, aumentaria em $7 \%$ a probabilidade de inovar.

Nos resultados desse modelo, chama atenção a importância da qualificação da mão-de-obra na probabilidade de a firma inovar. Das quatro variáveis que mais afetam a probabilidade de a firma ser uma inovadora, duas delas estão diretamente vinculadas à mão-de-obra: treinamento e escolaridade. Estas duas variáveis são determinantes importantes para as firmas competirem nos mercados doméstico e internacional. Cabe destacar que a variável treinamento da mão-de-obra está estreitamente vinculada à inovação de processo, uma vez que esse tipo de inovação depende da aquisição de máquinas e equipamentos, que, por sua vez, gera necessidade de treinamento específico da mão-de-obra.

\section{Desempenho no Comércio Exterior das Firmas que Realizam Internacionalização com Foco na Inovação Tecnológica}

A literatura sobre o tema demonstra que inovação tecnológica e rendimentos crescentes de escala da firma estão incluídos entre os determinantes das exportações de um país. Na seção anterior, identificamos que as características da mão-de-obra empregada é uma das variáveis especialmente relevantes para a firma tornar-se uma inovadora. No caso brasileiro, há evidências de que a qualidade da mão-de-obra também é importante para as firmas competirem no mercado internacional via exportações. Se o Brasil já está inserido nos mercados internacionais em que rendimentos crescentes de escala e inovação são os principais fatores de competição entre as firmas, qual seria a importância da internacionalização com foco na inovação tecnológica para aumentar a probabilidade de uma firma ser exportadora ou importadora?

Para responder a essa questão, dois modelos probabilísticos foram estimados. No primeiro, a variável dependente é a condição de a firma ser ou não exportadora, e, no segundo, a variável dependente é a condição de a firma ser ou não importadora. As variáveis explicativas são dummies por categoria de firmas criadas neste trabalho e dummies por divisão de acordo com a Classificação Nacional de Atividades Econômicas - CNAE. A categoria de referência é a NAC_ISOLADA. Os resultados são apresentados na Tabela 8. 
O Impacto da Internacionalização com Foco na Inovação Tecnológica...

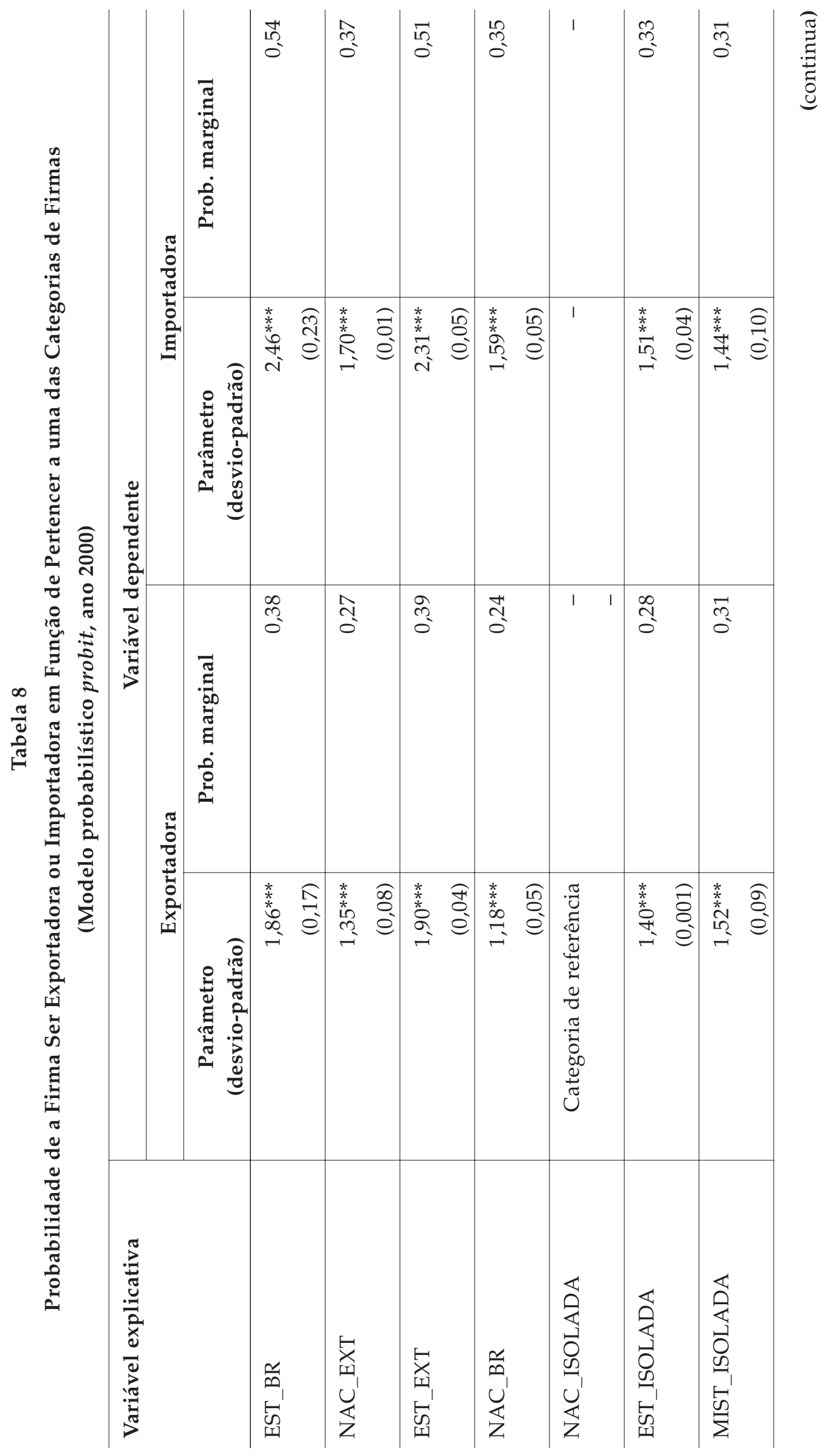




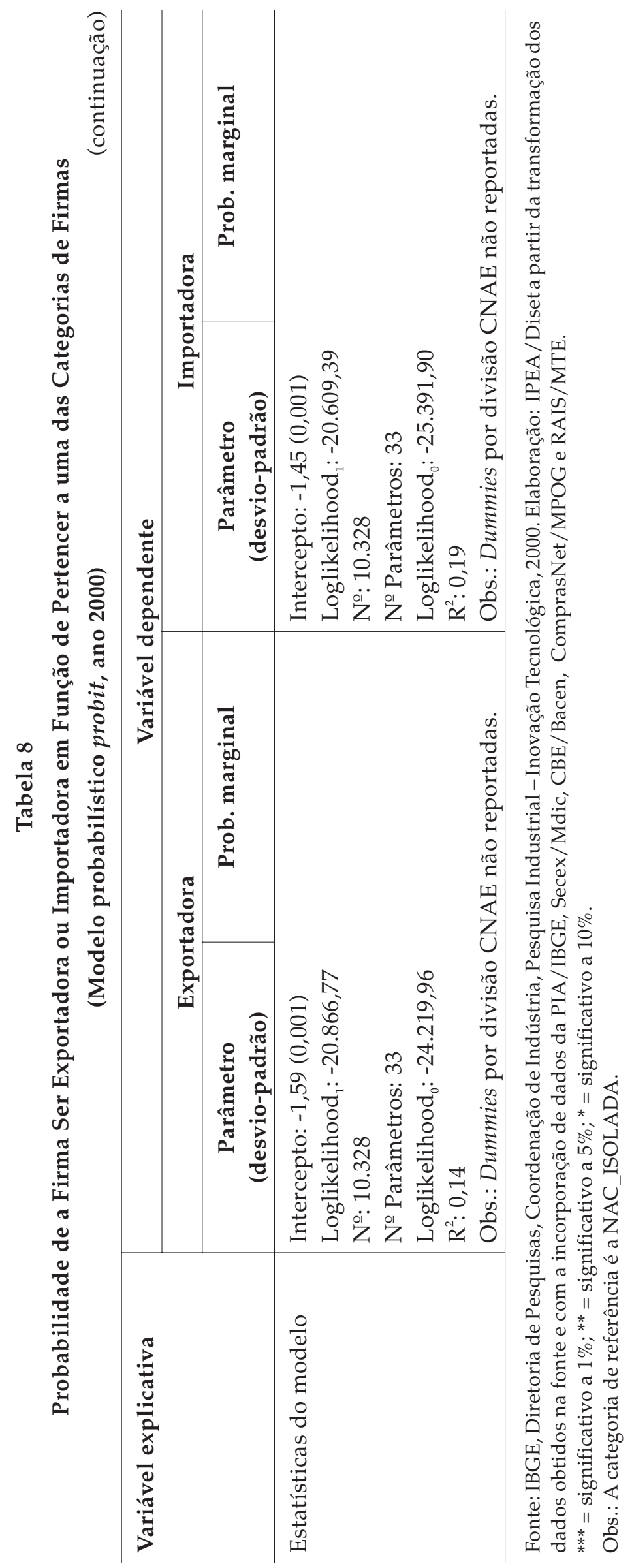


Os resultados da Tabela 8 mostram que, nas categorias de firmas que realizam processos de internacionalização com foco na inovação (categorias EST_BR, NAC_EXT e EST_EXT), a probabilidade de a firma ser exportadora é maior do que na categoria NAC_ISOLADA. Para as categorias EST_BR e EST_EXT, compostas de firmas com capital controlador estrangeiro, a probabilidade de a firma ser exportadora, caso ela pertença a uma dessas duas categorias, é, respectivamente, 38\% e 39\% maior do que na categoria NAC_ISOLADA. Se a firma pertence à categoria NAC_EXT, ela tem $27 \%$ mais chances de ser uma exportadora do que se pertencesse à categoria NAC_ISOLADA. Esses números mostram que a internacionalização com foco na inovação é positivamente correlacionada com a probabilidade de a firma ser exportadora, e particularmente maior quando ela é de capital controlador estrangeiro. A presença de capital estrangeiro nas categorias EST_ISOLADA e MIST_ISOLADA e o esforço inovador das firmas da categoria NAC_BR possivelmente deve ter afetado positivamente a probabilidade de a firma ser uma exportadora em relação à categoria NAC_ISOLADA, mesmo sendo estas categorias não internacionalizadas com foco na inovação.

Em relação à probabilidade de a firma ser importadora, os resultados mostraram que a internacionalização com foco na inovação parece afetá-la positivamente. Nas categorias EST_BR, NAC_EXT e EST_EXT, tal probabilidade aumenta, respectivamente, $54 \%, 37 \%$ e $51 \%$ em relação à categoria NAC_ISOLADA. Esses números são maiores em comparação aos das firmas que não realizam internacionalização com foco na inovação. Ou seja, nas categorias NAC_BR, EST_ISOLADA e MIST_ISOLADA, a probabilidade de a firma ser uma importadora aumenta, respectivamente, 35\%, 33\% e 31\%. Mais uma vez, quando o capital controlador é estrangeiro, a probabilidade de ela ser uma importadora aumenta mais do que quando o controle é nacional ou misto.

Na categoria NAC_EXT, apesar da maior probabilidade da firma ser importadora do que exportadora, o saldo comercial é positivo em mais de US $\$ 0,5$ bilhão. Na categoria NAC_BR, o saldo comercial é negativo em mais de US $\$ 3$ bilhões. Na categoria NAC_ISOLADA, as firmas, em média, exportam e importam pouco, mas o saldo é positivo em mais de US\$ 1 bilhão.

A evidência de que a probabilidade de a firma ser uma exportadora aumenta se ela realiza internacionalização com foco na inovação tecnoló- 
gica não qualifica o tipo de inserção dela no comércio exterior. Essa inserção será tanto mais virtuosa quanto maior for o preço que ela conseguir cobrar pelo seu produto exportado, quando comparado ao preço dos demais exportadores de um mesmo país. A internacionalização com foco na inovação tecnológica aumenta a chance de uma firma instalada no Brasil obter preço prêmio nas suas exportações em relação aos demais exportadores brasileiros? Esta questão é especialmente relevante porque há uma relação direta entre a agregação de valor ao produto exportado e o preço prêmio relativo aos exportadores de um mesmo país. Essa agregação de valor é uma condição importante para a inserção virtuosa de um país no comércio internacional.

Para verificar se a internacionalização está correlacionada com a obtenção do preço prêmio nas exportações, foi estimado um modelo probabilístico em que a variável dependente é a condição de a firma exportar com preço prêmio, e as variáveis independentes representam a condição de a firma ter obtido as informações necessárias para a inovação tecnológica no exterior e por diferentes caminhos. Deve-se ressaltar que a firma pode obter no exterior informações de diversas fontes: participando de eventos, comprando informações de centros de pesquisa, contratando consultoria etc., ou por intermédio de uma outra empresa do mesmo grupo no exterior. A especificação do modelo foi detalhada, por meio das variáveis explicativas, de maneira a mapear todas as possíveis formas de a firma obter no exterior informações para a inovação. O objetivo dessa especificação é verificar qual tipo de fonte no exterior é mais importante para a obtenção de preço prêmio nas exportações. Participar de um grupo empresarial com empresa no exterior é a melhor forma de a firma obter preço prêmio nas exportações?

Neste trabalho, o preço prêmio foi calculado por produto e mercado de referência. Considerou-se que a firma obteve preço prêmio de exportação caso o preço do bem exportado pela mesma estivesse $30 \%$ acima do preço médio exportado pela indústria brasileira ${ }^{13}$. Foram considerados três mercados de referência: Estados Unidos, Europa e América Latina. Foram estimados quatro modelos. No primeiro, a variável dependente é a condição de a firma ter obtido preço prêmio em qualquer um dos três mercados de referência. Nos outros três modelos, a variável dependente é a condição de a firma ter exportado com preço prêmio para cada um dos mercados de referência. Os resultados estão apresentados na Tabela 9. 
O Impacto da Internacionalização com Foco na Inovação Tecnológica...

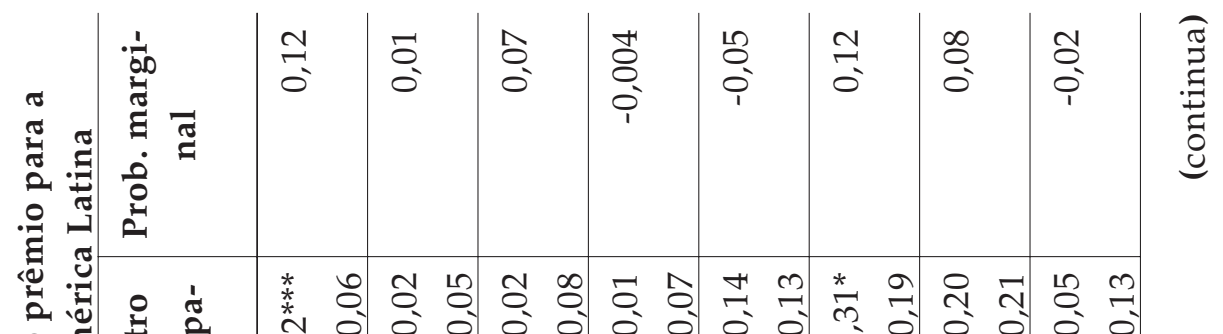

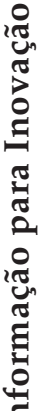

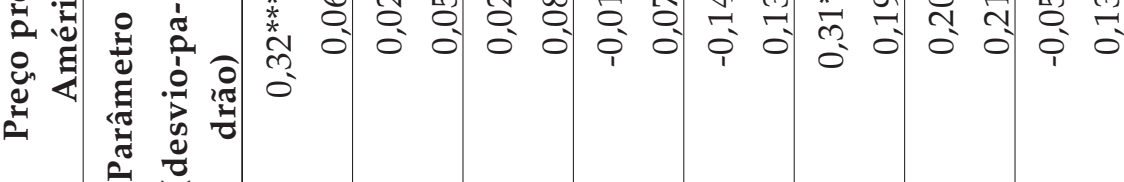

\begin{tabular}{|c|c|c|c|c|c|c|c|c|c|}
\hline 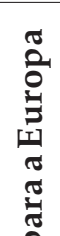 & 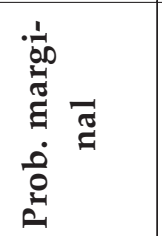 & $\stackrel{\sim}{\stackrel{2}{\sigma}}$ & 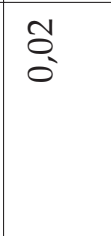 & $\stackrel{\circ}{\stackrel{2}{0}}$ & 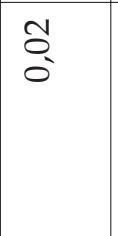 & $\begin{array}{l}n \\
0 \\
0 \\
1\end{array}$ & $\begin{array}{l}\text { Lo } \\
0 \\
0 \\
1\end{array}$ & $\begin{array}{l}0 \\
0 \\
0\end{array}$ & $\begin{array}{l}0 \\
0 \\
0\end{array}$ \\
\hline • & 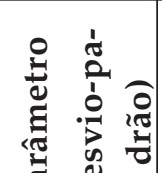 & 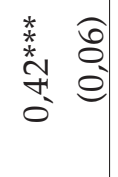 & $\begin{array}{ll}\infty & 0 \\
0 & 0 \\
0 & 0\end{array}$ & \begin{tabular}{ll} 
& $\infty$ \\
\multirow{x}{*}{} & 0 \\
Ln & 0 \\
$M$ & 0 \\
0 &
\end{tabular} & $\begin{array}{ll}1 & \infty \\
0 & 0 \\
0 & 0\end{array}$ & 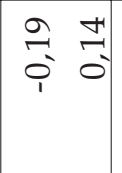 & 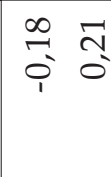 & 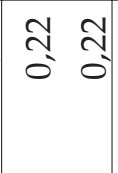 & $\begin{array}{ll}\stackrel{m}{0} & m \\
0 & 0\end{array}$ \\
\hline
\end{tabular}

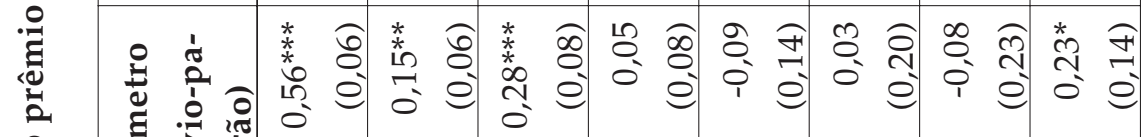

a.

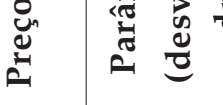

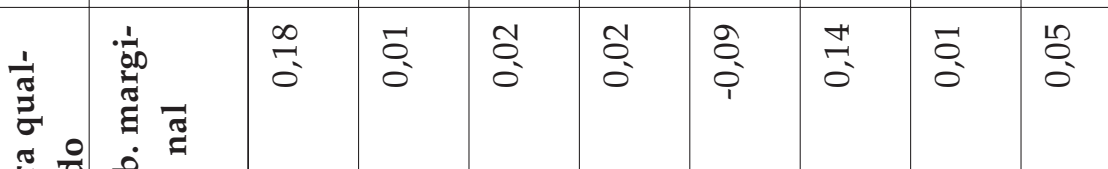

ฮี

월

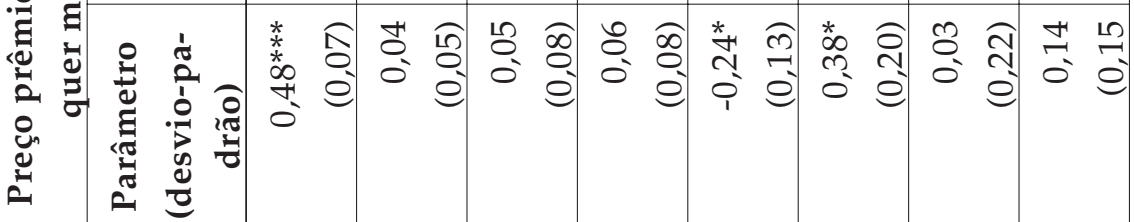

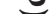

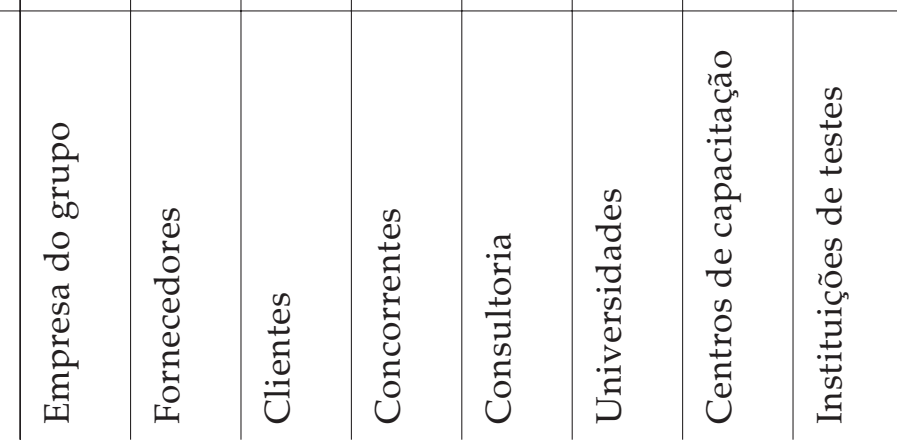




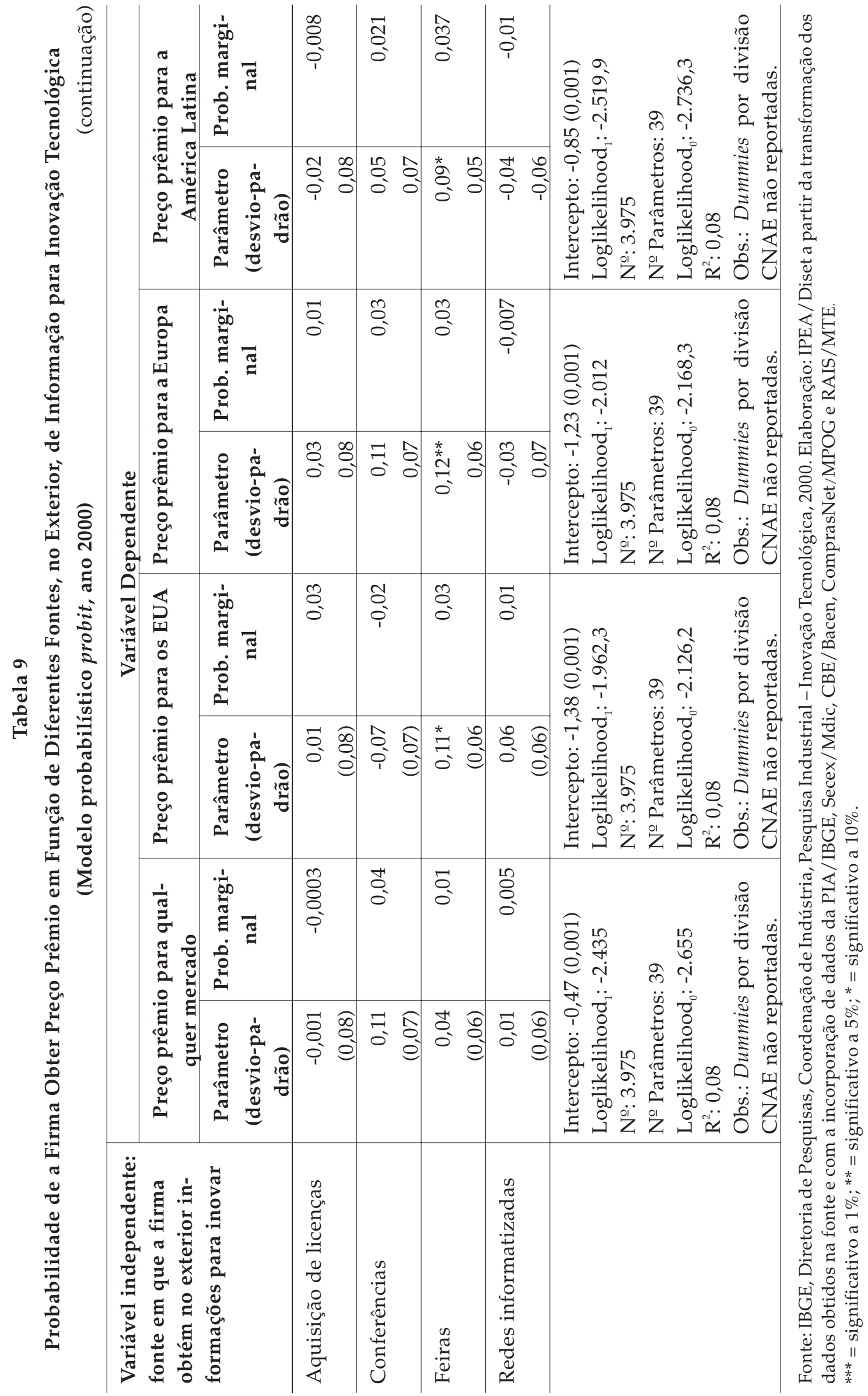


O primeiro resultado importante do modelo de preço prêmio é a estimativa de que a probabilidade de a firma exportadora no Brasil obtê-lo em relação aos demais exportadores da indústria brasileira, para os mercados dos Estados Unidos, Europa ou América Latina, aumenta em 18\% caso ela obtenha as informações necessárias para realizar inovação tecnológica de outra empresa do seu grupo empresarial no exterior. Ou seja, a internacionalização com foco na inovação tecnológica está positivamente relacionada à obtenção de preço prêmio nas exportações e, portanto, à agregação de valor aos bens exportados pelas firmas brasileiras. Os resultados são consistentes quando as estimativas são realizadas para cada mercado de referência.

O segundo resultado relevante do modelo é que as demais fontes de informação no exterior, que não a participação em um grupo empresarial internacionalizado, não são significativas do ponto de vista estatístico, ou são pouco importantes para a firma obter preço prêmio nos seus bens exportados.

No caso de preço prêmio para os Estados Unidos, as informações para inovação provenientes de fornecedores e clientes no exterior estão também positivamente correlacionadas com a obtenção de preço prêmio. Para a Europa, as informações que têm como fonte os clientes estão positivamente correlacionadas com o preço prêmio. No caso da América Latina, essas fontes não são importantes para obtenção de preço prêmio. Considerando que a exigência do consumidor no mercado da Europa e dos Estados Unidos é maior do que no mercado brasileiro, no qual a firma exportadora realiza sua produção, esses resultados parecem estar de acordo com o que seria esperado. É razoável acreditar que, nos mercados mais exigentes, como Europa e Estados Unidos, vis-à-vis a América Latina, as firmas que realizam inovações tecnológicas com informações dos clientes e fornecedores podem adequar melhor seu produto à demanda externa e, com isso, obter um diferencial de preços sobre as firmas que não levam em conta tais informações. Nos mercados menos exigentes ou mesmo naqueles tão exigentes quanto o do país onde a firma está instalada, que parece ser o caso das firmas brasileiras que exportam para o mercado da América Latina, as firmas não precisam contar com informações adicionais do país de destino da mercadoria para realizar inovações. Desta forma, não haveria um diferencial relativo de preços originado de firmas que buscam informações em clientes e fornecedores no exterior. 
Em síntese, do ponto de vista da corrente de comércio, foram encontradas evidências de que as firmas que se internacionalizam com foco na inovação têm maior probabilidade de serem exportadoras vis-à-vis as firmas que não realizam esse tipo de internacionalização. Foram também encontradas evidências de que as firmas brasileiras que se internacionalizam com foco na inovação conseguem obter um diferencial positivo de preço nos bens exportados, quando comparados com os demais exportadores da indústria brasileira. Desta maneira, é plausível acreditar que a internacionalização voltada para a inovação, além de promover a inserção externa da firma, torna mais virtuosa sua inserção no comércio internacional, pois aumenta a agregação de valor ao produto exportado.

\section{A IMPORTÂNCIA DO APOIO GOVERNAMENTAL E ARRANJOS COOPERATIVOS PARA A FIRMA REALIZAR INOVAÇÃO TECNOLÓGICA}

Neste trabalho, detalhamos as características de diferentes categorias de firmas de acordo com a origem do capital controlador e sua internacionalização com foco na inovação tecnológica. De maneira geral, observamos que as firmas de capital nacional ou misto que realizam processos de internacionalização com foco na inovação tecnológica são mais competitivas do que a grande maioria das firmas na indústria brasileira, e suas características se assemelham àquelas estrangeiras, que são reconhecidamente mais competitivas.

No Brasil, há diversos tipos de apoio governamental que as firmas podem usar para alavancar seu esforço inovador. $O$ apoio governamental está relacionado principalmente ao financiamento de atividades vinculadas à inovação tecnológica da firma. Além do apoio público, muitas cooperam com outras organizações com o objetivo de desenvolver inovações. Qual é a importância do a poio financeiro público e da cooperação para as diferentes categorias de firmas? A Tabela 10 mostra o percentual de firmas, em cada categoria, que receberam apoio público para o financiamento de atividades relacionadas à inovação tecnológica, assim como o percentual das que estiveram envolvidas em arranjos cooperativos com outras organizações a fim de desenvolver atividades inovadoras.

Com relação aos recursos financeiros públicos, observamos que os maiores percentuais estão nas categorias NAC_EXT, NAC_BR e MIST_ISOLADA, que são formadas por firmas de capital nacional ou 
Tabela 10

Distribuição Percentual das Firmas que Receberam Recursos Financeiros de Fontes Públicas ou Estiveram Envolvidas em Arranjos Cooperativos com Outras

Organizações a fim de Desenvolver Atividades de Inovação Tecnológica, por Categoria, em 2000

\begin{tabular}{l|c|c}
\hline Categorias & $\begin{array}{c}\text { Receberam Recursos Fi- } \\
\text { nanceiros Públicos }\end{array}$ & Realizaram Cooperação \\
\hline EST_BR & 5,9 & 37,5 \\
NAC_EXT & 14,6 & 27,1 \\
EST_EXT & 5,1 & 36,9 \\
NAC_BR & 13,1 & 38,8 \\
NAC_ISOLADA & 3,8 & 8,8 \\
EST_ISOLADA & 1,3 & 19,7 \\
MIST_ISOLADA & 10,2 & 15,1 \\
\hline
\end{tabular}

Fonte: IBGE, Diretoria de Pesquisas, Coordenação de Indústria, Pesquisa Industrial - Inovação Tecnológica, 2000. Elaboração: IPEA/Diset a partir da transformação dos dados obtidos na fonte e com a incorporação de dados da PIA/IBGE, Secex/Mdic, CBE/Bacen, ComprasNet/MPOG e RAIS/MTE.

misto. Mais de $10 \%$ das firmas em cada uma dessas categorias receberam algum tipo de apoio financeiro público para alavancar suas atividades de inovação tecnológica. No entanto, é importante observar que 5\% das firmas estrangeiras da categoria EST_EXT recebem apoio público. Como nesta categoria está concentrada a maior parte dos gastos em atividades voltadas à inovação, é possível que essas firmas absorvam um volume considerável de recursos provenientes do setor público. A Tabela 10 mostra também que a cooperação pode ser um elemento importante para se obter êxito no processo de inovação, uma vez que nas categorias EST_BR, NAC_EXT, EST_EXT e NAC_BR há maior percentual de firmas que cooperam, sendo maior também o percentual de firmas inovadoras.

Para dimensionar a importância de diversas fontes de recursos na probabilidade de ela ser uma inovadora, foram estimados três modelos probabilísticos. A condição de a firma ser inovadora, inovadora de produto ou inovadora de processo foi explicada pela participação relativa de fontes própria, privada ou pública sobre o total de gastos em P\&D e pela participação relativa de fontes própria, privada ou pública sobre o total de outros gastos em atividades relacionadas com inovação tecnológica. Os resultados foram apresentados na Tabela 11. 


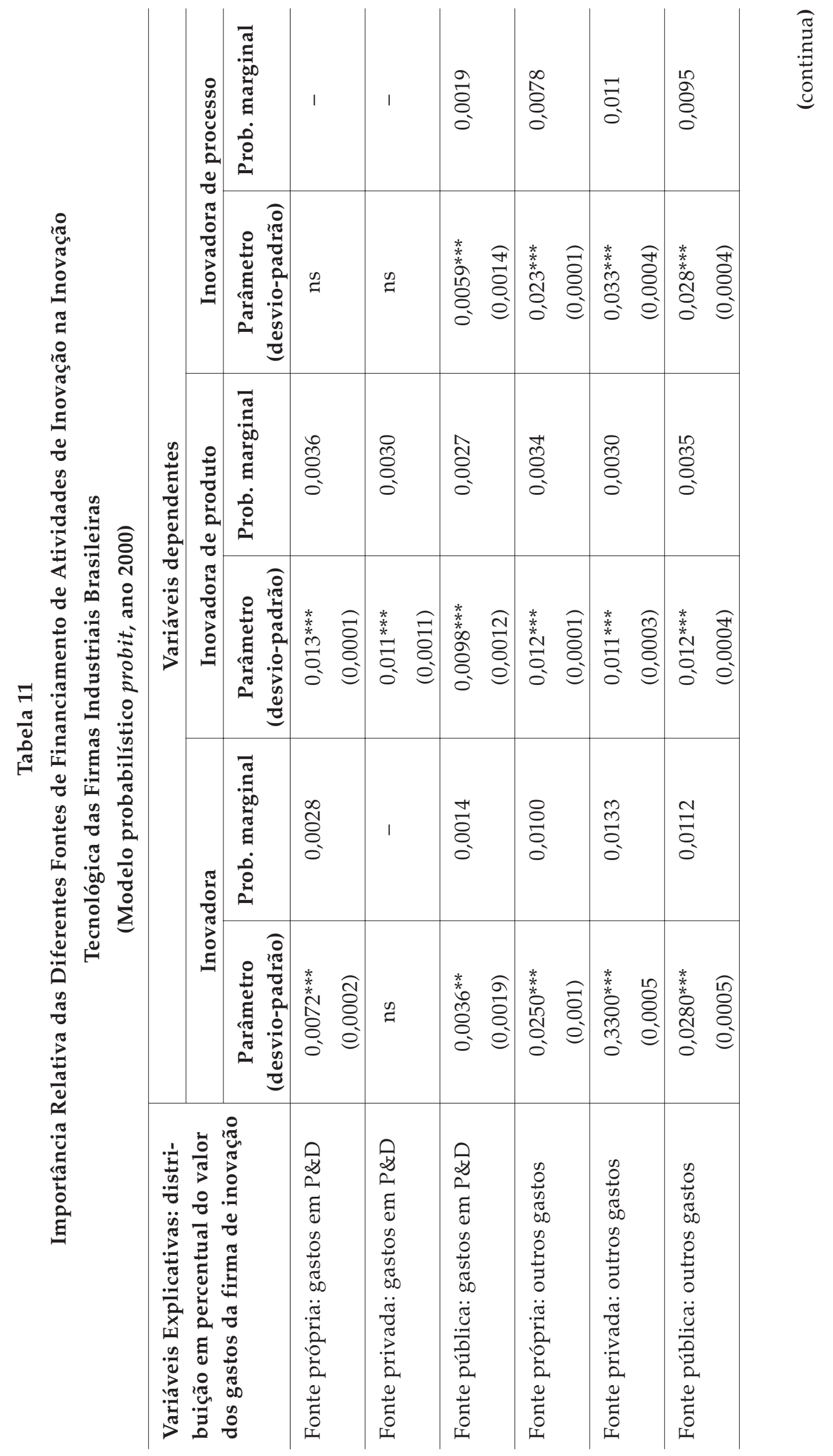


O Impacto da Internacionalização com Foco na Inovação Tecnológica...

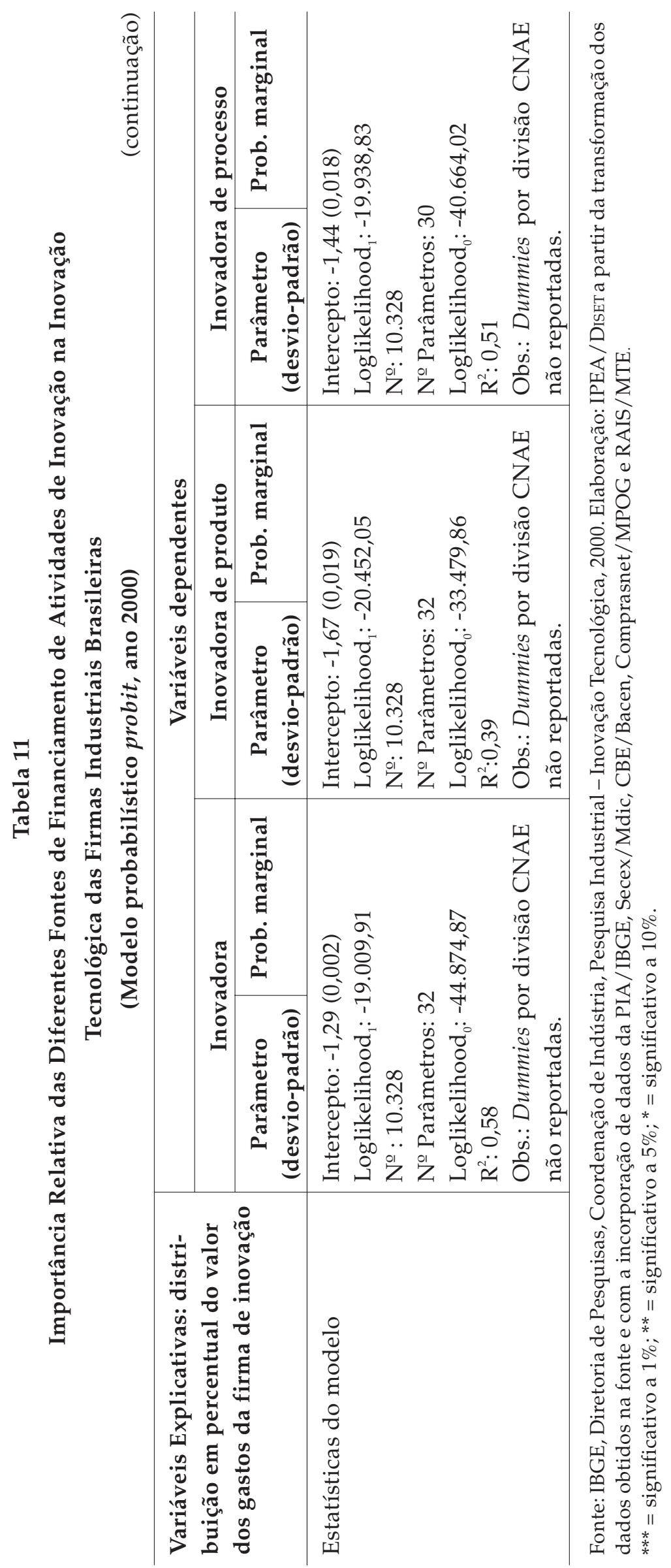


A análise dos resultados pode ser feita diretamente sobre a probabilidade marginal. No caso dos gastos em $\mathrm{P} \& \mathrm{D}$, a fonte de recursos própria é duas vezes mais importante para a firma alcançar a inovação tecnológica do que quando a fonte de recursos é pública. Os resultados mostram que um aumento na participação das fontes próprias em dez pontos percentuais sobre o total dos gastos em P\&D aumentaria em $2,8 \%$ a probabilidade de a firma realizar inovação tecnológica. Se a fonte pública de financiamento para as atividades de P\&D aumentar em dez pontos percentuais, a probabilidade de as firmas realizarem inovações tecnológicas aumenta em 1,4\%. Ainda com relação aos gastos em $\mathrm{P} \& \mathrm{D}$, no caso da inovação de produto, a fonte de gastos próprios continua sendo a mais importante para determinar a probabilidade de a firma ser uma inovadora de produto, seguida por fontes privadas e, por último, por fontes públicas; no caso da inovação de processo, as fontes privada e própria não foram significativas, e a fonte pública tornou-se a principal variável explicativa da probabilidade de a firma inovar em processo.

Com relação aos outros gastos em atividade de inovação tecnológica, observa-se pelos resultados da Tabela 11 que a importância das diferentes fontes de financiamento na determinação de as firmas serem inovadoras parece ser relativamente a mesma nos três modelos. No caso da inovação de processo, a fonte pública parece ser relativamente mais importante que as outras fontes de financiamento, o que parece ser razoável porque as fontes públicas de financiamento como BNDES e Banco do Brasil financiam compras de máquinas e equipamentos utilizados na inovação de processo.

Em síntese, esta seção encontrou evidências de que a cooperação é possivelmente um elemento importante para as firmas realizarem inovações tecnológicas, pois nas categorias EST_BR, NAC_EXT, EST_EXT e NAC_BR, nas quais o percentual de firmas que realizou inovações tecnológicas é maior, também é maior o percentual de firmas que participam de arranjos cooperativos. Nessas categorias, também é maior o percentual de firmas que receberam recursos de instituições públicas para realizar inovações tecnológicas, o que seria uma evidência de que esses recursos públicos estariam sendo direcionados para firmas mais inovadoras e estão positivamente relacionados com a probabilidade de a firma realizar uma inovação tecnológica. Há também alguma evidência de que uma parte significativa dos recursos públicos esteja sendo destinada para firmas de capital estrangeiro. Os resultados também 
mostraram que os recursos públicos são mais importantes para inovação de processo do que de produto e que, no caso dos gastos em P\&D, os recursos próprios ganham mais relevância.

Tais resultados têm implicações importantes para a Política Industrial, Tecnológica e de Comércio Exterior que o governo federal vem construindo e implementando, e que possui a inovação como seu ponto central. Uma vez que a indução da inovação passa por reduzir o custo e o risco privados, devem ser elaborados instrumentos adequados. Assumindo, porém, que a inovação mais relevante é aquela voltada para o mercado (inovação de produto), temos a prevalência do gasto privado como variável explicativa. Se é fato que, no ano base das a nálises aqui realizadas (2000), não havia o empuxo exportador atual, os dados mostram que é absolutamente relevante estimular o gasto privado em P\&D; um dos aspectos importantes a serem tratados pela Agência Brasileira de Desenvolvimento Industrial é a redução do risco da inovação não só para pequenas e médias, mas também para grandes empresas.

\section{CONCLUSÃO}

A conclusão deste trabalho se volta para a seguinte questão: quais são os parâmetros para o governo apoiar a internacionalização das firmas brasileiras?

A análise aqui desenvolvida demonstrou que existem benefícios resultantes da internacionalização da firma com foco na inovação tecnológica. Verificou-se que essas empresas remuneram melhor a mão-de-obra, empregam pessoal com maior escolaridade e, portanto, geram empregos de melhor qualidade. Além disso, apresentam, relativo ao faturamento, maior percentual de dispêndio em treinamento de mão-de-obra, o que impulsionaria de alguma forma a qualificação da mão-de-obra doméstica. Com relação às características da firma, observou-se que as internacionalizadas com foco na inovação exportam mais do que as que não fazem esse tipo de internacionalização, além de agregar valor aos bens exportados. Portanto, há evidências de que o aumento da competitividade das firmas é influenciado positivamente pelas inovações tecnológicas resultantes do processo de internacionalização, e que tal competitividade auxilia nas exportações de bens de maior valor adicionado. A abertura de mercados externos geraria maior potencial de expansão e crescimento da firma e também a própria in- 
ternacionalização geraria mecanismos de retroalimentação da sua capacitação tecnológica.

A internacionalização com foco na inovação tecnológica das firmas industriais brasileiras é, nesse sentido, um componente especialmente relevante da inserção internacional do Brasil, e há espaço para políticas públicas que incentivem a internacionalização com esse intuito. É importante ressaltar que a inovação tecnológica exibe rendimentos crescentes a longo prazo, não quantificáveis em exercícios estáticos e, portanto, não comparáveis com os custos de curto prazo. Entretanto, o custo de curto prazo de uma política de incentivo, como, por exemplo, uma linha de financiamento a longo prazo para estimular a internacionalização, pode ser relativamente reduzido se esta for focada na inovação tecnológica e restrita por ações pré-estruturadas que estabeleçam como critérios fazer com que as firmas de capital nacional que já fazem significativo esforço para realizar inovações tecnológicas ampliem seu potencial de inovação internacionalizando-se. Desta maneira, ficaria evidente que a ação pública deve levar em conta exemplos de êxitos empresariais nacionais que poderiam ser seguidos por outras firmas de capital nacional, principalmente por aquelas que já fazem esforço inovador significativo. Deve ser ressaltado que os incentivos à internacionalização com foco na inovação tecnológica devem estar também associados a mecanismos que estimulem o aumento dos gastos privados em atividades voltadas para a inovação tecnológica no Brasil.

Dos resultados deste trabalho, chama a atenção a importância da qualificação da mão-de-obra na probabilidade de a firma inovar. Das quatro variáveis que mais afetam esta probabilidade, duas estão diretamente vinculadas à mão-de-obra: treinamento e escolaridade. Nesse sentido, há um parâmetro importante para a política pública de longo prazo. Se a escolarização da força de trabalho por si só não vai levar automaticamente à inovação e à internacionalização das empresas, os dados mostram que as empresas que se internacionalizaram com foco na inovação empregam mão-de-obra mais escolarizada. Assim, uma política de incentivo à inovação na indústria passa por políticas de aumento da escolaridade da população.

Deve ser destacado também que um dos resultados deste trabalho é a evidência de que a cooperação é possivelmente um elemento importante para as firmas realizarem inovações tecnológicas. Assim sendo e, portanto, verificando-se que há busca de informação conjunta entre 
firmas que procuram inovar, há espaço para o poder público atuar na promoção de ações que procurem no exterior informações sobre oportunidades de negócio e que podem ser realizadas de forma compartilhada entre uma agência de promoção de desenvolvimento industrial e grupos empresariais interessados em internacionalizar-se com foco na inovação.

(Recebido para publicação em agosto de 2004)

(Versão definitiva em março de 2005)

\section{NOTAS}

1. Antes de Lafetá Machado (1997), os trabalhos de Tyler (1972), Rocca e Barros (1972) e Carvalho e Haddad (1977), também com base na abordagem da mão-de-obra, tinham encontrado evidências do padrão H-O para o Brasil.

2. Para explicar esta característica do comércio internacional entre países foram formuladas teorias baseadas nas hipóteses chamberlianas de diferenciação do produto, economias de escala e competição monopolista. A incorporação dos rendimentos crescentes de escala aos modelos de comércio internacional trouxe um arcabouço complementar à explicação do comércio internacional dos modelos H-O. Os modelos de comércio chamberlianos podem ser encontrados nos trabalhos de Krugman (1979; 1981), Lancaster (1980), Helpman (1981) e Helpman e Krugman (1985).

3. Braga e Mascolo (1980) encontraram evidências de que o tamanho exerce considerável influência sobre a rentabilidade das firmas na indústria brasileira.

4. Nesta mesma direção, Markwald e Puga (2002) mostraram que $85,5 \%$ das grandes firmas industriais são exportadoras, e que este percentual cai para 40,6\% quando a firma é média, e para 12,4\% quando é pequena. Veiga e Markwald (1997) verificaram que a participação das pequenas e médias empresas nas exportações brasileiras é pequena e não constante, a pesar de grande número destas firmas estar anualmente presente na base exportadora.

5. Entre as teorias que buscam explicações para a internacionalização das firmas, destaca-se a eclética desenvolvida por Dunning (1988; 1991; 1993). Segundo esta teoria, custos de transação e informação, oportunismo dos agentes e especificidades dos ativos são as bases dos determinantes do investimento externo de uma firma. Sobre custos de transação, ver Coase (1991) e Williamson (1985).

6. A Pintec/IBGE é a Pesquisa Industrial de Inovação Tecnológica "realizada pelo IBGE, que tem como objetivo gerar um conjunto de indicadores setoriais para as atividades de inovação tecnológica da indústria brasileira. Realizada pelo IBGE com o apoio da FINEP, adota a metodologia recomendada no Manual de Oslo e, mais especificamente, o modelo proposto pelo EUROSTAT, a terceira versão da Community 


\section{Glauco Arbix, Mario Sergio Salerno e João Alberto De Negri}

Innovation Survey (CIS) 1998-2000, da qual participam os 15 países membros da comunidade européia. Os resultados da Pintec são relativos às empresas industriais com 10 ou mais empregados, cerca de 70 mil no país" (IBGE, 2002).

7. O segmento automotivo apresentou déficits consideráveis pós-regime automotivo (1997-2002). A balança do setor de autopeças só ficou positiva em 2003.

8. Ver Arbache e De Negri (2002) e De Negri e Acioly (2004).

9. A Pintec possui informações sobre os gastos realizados nas aquisições de máquinas e equipamentos utilizados para a inovação tecnológica. Esta variável não foi reportada na Tabela 5 por uma questão metodológica. Os investimentos das firmas em máquinas e equipamentos muitas vezes são superiores ao faturamento anual da firma ou então representam um percentual grande em relação ao faturamento do ano. Essas máquinas geralmente são compradas com carência e prazos de amortização relativamente longos, pois esta é a dinâmica do mercado de bens de capital. Desta maneira, a relação dispêndio/faturamento para essa variável daria a falsa impressão de que a firma teria comprometido significativamente o seu faturamento anual, o que não é verdade pelas condições de financiamento nesse segmento.

10. Fleury (1997), estudando o comportamento de empresas multinacionais com relação a atividades de engenharia, mostra a concentração de $P \& D$ e engenharia básica nas matrizes, com as subsidiárias focando na engenharia de processo; Salerno et alii (2003; 2004), a partir de extenso survey no setor automotivo (incluindo matrizes), introduzem o conceito de sede de projeto, que guarda íntima relação com a escolha local de fornecedores.

11. Em termos absolutos, as estrangeiras investem mais; no entanto, estimativas preliminares realizadas por Araújo (2004) mostram que as firmas de capital nacional investem proporcionalmente mais em $\mathrm{P} \& \mathrm{D}$ em relação ao faturamento do que as de capital estrangeiro.

12. Os modelos foram estimados inicialmente com a variável gastos em máquinas e equipamentos. Esta variável apresentou uma correlação acima de 0,5 com a variável dispêndio em treinamento da mão-de-obra. Muito provavelmente, as compras de máquinas e equipamentos são acompanhadas de gastos com o treinamento da mão-de-obra para operar essas máquinas e processos, o que deve ocorrer com freqüência nas firmas que introduzem inovações de processo. Para evitar os problemas de multicolinearidade, a variável dispêndio com máquinas e equipamentos foi retirada do modelo.

13. Dois problemas metodológicos podem surgir quando o preço prêmio é estimado para cada produto e mercado. Primeiro, a firma pode exportar mais de um produto para um mesmo mercado. Nesse caso, o preço prêmio seria calculado para cada produto da firma e, posteriormente, seria estimada a média do preço prêmio ponderada pelo valor dos produtos exportados pela firma. Segundo, ela pode ser a única exportadora brasileira de um produto específico para um determinado mercado. Nesse caso, não haveria preço prêmio, pois o preço médio da indústria é o preço médio da firma. A idéia de preço prêmio está, entretanto, vinculada também à idéia de competitividade, pois firmas que obtêm preço prêmio são as mais competitivas. Se ela é a única firma capaz de exportar um produto, não seria razoável dizer que a mesma não é competitiva em relação às demais firmas da indústria brasileira. Para contornar esse problema, a exigência de que o preço do bem exportado pela firma esteja $30 \%$ 
acima da média da indústria, para definir se a firma obteve preço prêmio, foi ponderada pelo complemento da participação da firma no total exportado pela indústria brasileira no mercado de referência. O procedimento metodológico está detalhado no anexo deste trabalho.

\section{REFERÊNCIAS BIBLIOGRÁFICAS}

ARBACHE, J. S. e DE NEGRI, J. A. (2002), “Diferenciais de Salários Interindustriais no Brasil: Evidências e Implicações". Texto para Discussão, no 918, IPEA.

ARAÚJO, R. D. (2004),Desempenho Inovador e Comportamento Tecnológico das Firmas Domésticas e Transnacionais no Final da Década de 90. Disertação de mestrado, Instituto de Economia/Unicamp.

BAUMANN, R. (1993), “Uma Avaliação das Exportações Intra-firma do Brasil: 1980 e 1990". Pesquisa e Planejamento Econômico, vol. 23, nº 3, pp. 487-512.

BNDES - Banco Nacional de Desenvolvimento Econômico e Social (1993), “Caracterização do Processo de Internacionalização de Grupos Econômicos Privados Brasileiros". Série Pesquisas Empresariais, $\mathrm{n}^{\circ}$ 1. Rio de Janeiro, BNDES.

BRAGA, C. H. e GUIMARÃES, E. P. (1985), “Estrutura Industrial e Exportações de Manufaturados: Brasil, 1878". Anais do XIII Encontro Nacional de Economia, da Associação Nacional dos Centros de Pós-Graduação em Economia - Anpec, Recife.

BRAGA, C.H. e HICKMANN, E. (1988), Produtividade e Vantagens Comparativas Dinâmicas na Indústria Brasileira - 1970-83. Trabalho apresentado no XVI Encontro Nacional da Anpec. Belo Horizonte, 5-7 de dezembro.

e MASCOLO, J. L. (1980), "A Influência do Tamanho sobre a Rentabilidade na Indústria Brasileira". Revista Brasileira de Economia, vol. 34, no 2, pp. 251-278.

BRASIL, H., LEONEL, J. N., ARRUDA, C. e GOULART, L. (1996), “Pesquisa de Campo sobre a Internacionalização das Empresas Brasileiras", in H. Brasil e C. Arruda (eds.), Internacionalização de Empresas Brasileiras. Rio de Janeiro, Quality-mark.

CARVALHO, J. L. e HADDAD, C. L. (1977), “Um Índice de Qualidade de Mão-de-Obra: Uma Aplicação ao Conceito de Capital Humano". Revista Brasileira de Economia, vol. 31, no 1 , pp. 31-43.

COASE, R. H. (1991) [1937], “The Nature of the Firm”, in O. E. Williamson e S. G. Winter (eds.), The Nature of the Firm Origins, Evolution, and Development. New York, Oxford University Press.

DE NEGRI, F. (2003), Desempenho Comercial das Empresas Estrangeiras no Brasil na Década de 90. Dissertação de Mestrado, Instituto de Economia, Universidade Estadual de Campinas. 
DE NEGRI, J. A. (2003), Rendimentos Crescentes de Escala e o Desempenho Exportador das Firmas Industriais Brasileiras. Tese de Doutorado, Departamento de Economia, Universidade de Brasília.

e ACIOLY, L. (2004), “Novas Evidências sobre os Determinantes do Investimento Externo na Indústria de Transformação Brasileira". Texto para Discussão, no ${ }^{1019}$, IPEA.

DUNNING, J. H. (1988), Explaining International Production. London, Unwin Hyman. . (1991), Multinational Enterprises and the Global Economy. London, Addison-Wesley Publishing Company.

. (1993), The Globalization of Business: The Challenge of the 1990s. London, Routledge.

FLEURY, Afonso. (1997), “Estratégias, Organização e Gestão de Empresas em Mercados Globalizados: A Experiência Recente do Brasil". Gestão \& Produção, vol. 4, noำ pp. 264-277.

HECKSCHER, E. (1919) [1949], “The Effect of Foreign Trade on the Distribution of Income". Ekonomisk Tidskrift, pp. 497-512. (Republicado em A.E.A. readings in the Theory of International Trade. Blakiston. Philadelphia, 1949. Cap. 13, p. 272-300).

HELPMAN, E. (1981), "International Trade in the Presence of Product Differentiation, Economies of Scale and Monopolistic Competition: A Chamberlin-Heckscher-Ohlin Approach". Journal of International Economics, nํㅜ 11, pp. 305-340.

e KRUGMAN, P. (1985), Market Structure and Foreign Trade: Increasing Returns, Imperfect Competition and the International Economy. Cambridge, MIT Press.

HIDALGO, A. B. (1985), “Intensidades Fatoriais na Economia Brasileira: Novo Teste do Teorema de Heckscher-Olhin". Revista Brasileira de Economia, vol. 39, nº 1, pp. 27-55.

. (1990), "O Comércio Intra-industrial Brasileiro". Anais do XVIII Encontro Nacional de Economia, Anpec, Brasília.

. (1993), “Mudanças na Estrutura do Comércio Internacional Brasileiro: Comércio Interindústria x Comércio Intra-indústria". Anais do XXI Encontro Nacional de Economia, Anpec, Belo Horizonte.

IBGE - Instituto Brasileiro de Geografia e Estatística. (2002), Pesquisa Industrial Inovação Tecnológica 2000 - Análise dos Resultados. Rio de Janeiro, IBGE.

IGLESIAS R. M. e MOTTA VEIGA, P. (2002), "Promoção de Exportações Via Internacionalização das Firmas de Capital Brasileiro", in A. C. Pinheiro, R. Markwald e L. V. Pereira (eds.), O Desafio das Exportações. Rio de Janeiro, BNDES.

KRUGMAN, P. (1979), “Increasing Returns, Monopolistic Competition and International Trade". Journal of International Economics, vol. 9, no 4, pp. 469-479.

. (1981), "Intra-industry Specialization and the Gains from Trade". Journal of Political Economy, vol. 89, no 51, pp. 956-973.

(1985), “A ‘Technology Gap’ Model of International Trade”, in K. Jungenfelt (ed.), Structural Adjustment in Advanced Economies. London, Macmillan.

LAFETÁ MACHADO, D. (1997), A Qualificação da Mão-de-Obra no Comércio Internacional Brasileiro: Um Teste do Teorema do Heckscher-Ohlin. Rio de Janeiro, BNDES (20ํㅡㄹ Prêmio BNDES de Economia). 
LANCASTER, K. (1980), "Intra-industry Trade under Perfect Monopolistic Competition". Journal of International Economics, nำ10, pp. 151-175.

MACHADO, J. B. M. (1992), “Comércio Regional e Especialização Produtiva: Uma Análise do Comércio Intra-industrial entre o Brasil e os Países da Aladi". Texto para Discussão, no 283, IE/UFRJ.

MARKWALD, R. e PUGA, F. (2002), “Focando a Política de Promoção de Exportações”. Texto para Discussão, no 160, Rio de Janeiro, Fundação Centro de Estudos do Comércio Exterior - Funcex.

OHLIN, B. (1933), Interregional and International Trade. Cambridge, Harvard University Press.

PAULA PINTO, M. B. (1981), “Os Efeitos dos Incentivos sobre a Estrutura das Exportações Brasileiras de Manufaturados". Estudos Econômicos, vol. 11, no 3, pp. 115-132.

. (1984), "Efeitos Alocativos da Política de Promoção de Exportações: Uma Reavaliação". Pesquisa e Planejamento Econômico, vol. 14, nº 2, pp. 547-560.

. (1994), “O Custo dos Recursos Domésticos e a Competitividade da Agricultura Brasileira". Estudos de Política Agrícola, no 27, IPEA.

PINHEIRO, A. C. e MOREIRA, M. M. (2000), “O Perfil dos Exportadores Brasileiros de Manufaturados nos Anos 90: Quais as Implicações da Política", in P. Motta Veiga (org.), O Brasil e os Desafios da Globalização. São Paulo/Rio de Janeiro, SOBEET/Relume Dumará, pp. 99-148.

ROCCA, C. A. e BARROS, J. R. M. de. (1972), “Recursos Humanos e Estrutura do Comércio Exterior". Estudos Econômicos, vol. 2, no 5, pp. 89-110.

SALERNO, M. S., MARX, R. e ZILBOVICIUS, M. (2003), "A Nova Configuração da Cadeia de Fornecimento na Indústria Automobilística no Brasil". Revista de Administração, vol. 38, no 3, pp. 192-204.

e DIAS, A. V. C. (2004), "Política Industrial em Setores Dominados por Transnacionais: O Brasil como Sede de Concepção e Projeto de Produto", in A. Fleury e M. T. L. Fleury (eds.), Política Industrial 2. São Paulo, Publifolha, pp. 67-91 (Coleção Biblioteca Valor).

SAVASINI, T.A.A. (1978), Export Promotions - The Case of Brazil. New York, Praeger Publishers.

e KUME, H. (1979), “Custos dos Recursos Domésticos das Exportações Brasileiras". Estudos CE, no 3, Funcex.

SAVASINI, J. A. A. et alii. (1974), “O Sistema Brasileiro de Promoção às Exportações”. Texto para Discussão, $\mathrm{n}^{\circ} 11$. IPEA/USP.

TEITEL, S. e THOUMI, F. E. (1986), “Da Substituição de Importações às Exportações: As Experiências Argentinas e Brasileiras no Campo das Exportações de Manufaturas". Pesquisa e Planejamento Econômico, vol. 16, no 1, pp. 129-166.

TYLER, W. G. (1972), “O Comércio de Manufaturados e a Participação do Mercado Brasileiro Especializado-O Caso Brasileiro". Estudos Econômicos, vol. 2, no 5, pp. 129-154.

VEIGA, P. e MARKWALD, R. (1997), "Pequenas e Médias Empresas nas Exportações”, in J. P. dos R. Velloso (ed.), O Brasil e o Mundo no Limiar do Novo Século. Rio de Janeiro, José Olympio, pp. 243-278 (Fórum Nacional).

WILLIAMSON, O. E. (1985), The Economic Institutions of Capitalism. New York, Free Press. 


\section{ANEXO \\ Estimativa de Preço Prêmio nas Exportações Utilizadas no Modelo da Tabela 9}

a) Considere as informações por produto, firma e mercado:

$i=$ produto exportado pela firma a 8 dígitos da Nomenclatura Comum do Mercosul

$j$ = firmas exportadoras por CNPJ a 8 dígitos;

$m=$ mercados específicos: Estados Unidos, Europa e América Latina;

b) Considere a relação de preço:

$\operatorname{Pr}_{i j m}=\frac{P p_{i j m}}{P m_{i m}}$

onde:

$\operatorname{Pr}_{j m}=$ Preço prêmio do produto " $i$ " da firma " $j$ " nas exportações para o mercado " $m$ ";

$P p_{i j m}=$ Preço do produto " $i$ " praticado pela firma " $j$ " nas exportações para o mercado " $m$ ";

$P m_{i m}=$ Preço médio praticado pela indústria brasileira para o produto " $j$ " nas exportações para o mercado " $m$ ";

$\operatorname{Pr}_{j m}=\frac{\sum_{i=1}^{n}\left(\operatorname{Pr}_{i j m}\right)\left(X_{i j m}\right)}{\sum_{i=1}^{n} X_{i j m}}$

onde:

$\operatorname{Pr}_{j m}=$ Preço prêmio ponderado pelas exportações dos " $n$ " produtos " $i$ " da firma " $j$ " nas exportações para o mercado " $m$ ";

$X_{i j m}=$ Valor Exportado do produto " $i$ " pela firma " $j$ " nas exportações para o mercado " $m$ ";

c) Considere a participação no mercado:

$S_{i j m}=\frac{\sum_{i=1}^{n} X_{i j m}}{\sum_{i=1}^{n} X_{i m}}$ 
onde

$S_{i j m}=$ participação da firma "j" nas exportações brasileiras do produto " $i$ " exportado para o mercado " $m$ ";

$X_{i j}=$ Valor Exportado do produto “i” pela indústria brasileira para o mercado " $m$ ";

$S_{j m}=\frac{\sum_{i=1}^{n}\left(S_{i j m}\right)\left(X_{i j m}\right)}{\sum_{i=1}^{n}\left(X_{i j m}\right)}$

onde:

$S_{j m}=$ Participação ponderada pelas exportações dos " $n$ " produtos " $i$ " da firma " $j$ " nas exportações brasileiras para o mercado " $m$ ";

d) Considere o limite de preço com preço prêmio de $30 \%$

$P l_{j m}=1+\left\lfloor 0,3\left(1-S_{j m}\right)\right\rfloor$

onde:

$P l_{j m}=$ preço limite da firma " $j$ " nas exportações brasileiras para o mercado " $m$ ";

e) Temos que:

Firma têm preço prêmio se e somente se:

Preço Prêmio $=\left\{\frac{1 \text { se } \operatorname{Pr}_{j m} \geq P l_{j m} \forall m}{0 \text { CasoContrário }}\right.$, onde $m=$ Mercado Europeu, Americano e Améria Latina 


\section{ABSTRACT \\ The Impact of Internationalization with a Focus on Technological Innovation and Brazilian Companies' Exports}

Based on an unprecedented link between the principal official databases on Brazilian industry - the Industrial Survey on Technological Innovation (Pintec) and the Annual Industrial Survey (PIA) of the National Census Bureau (IBGE); the foreign trade database of the Ministry of Development, Industry and Foreign Trade - Mdic, and the Annual Report on Social Data of the Ministry of Labor and Employment (RAIS/MTE) - this study showed that the companies that use their offices abroad as a source of information for technological innovation show superior performance to the rest: they are larger, import and export more, pay higher salaries, employ workers with more education, and spend relatively more on training activities. The probability of a company exporting increases by $16 \%$ when it invests in technological innovation. These results indicate the need to reflect on public policies to support innovation and internationalization in Brazilian companies.

Key words: technological innovation; Brazilian companies' exports; internationalization in Brazilian companies

\section{RÉSUMÉ}

L'Impact de l'Internationalisation Centrée sur l'Innovation Technologique dans les Exportations des Entreprises Brésiliennes

À partir d'une composition nouvelle des principales banques de données officielles concernant l'industrie brésilienne (Pintec et PIA/IBGE, Mdic-Commerce Extérieur, RAIS/MTE), on a vérifié que les entreprises qui se servent d'unités à l'étranger comme source d'information pour leur innovation technologique montrent des résultats supérieurs à ceux de leurs concurrents: leur taille est plus importante, leur flux d'importation-exportation est plus intense, elles paient les meilleurs salaires, emploient des travailleurs d'un meilleur niveau scolaire et financent beaucoup plus d'activités de formation. Les chances d'être d'une entreprise d'exportation grandissent de $16 \%$ quand elle adopte l'innovation technologique. Ces résultats montrent le besoin de réfléchir sur des politiques publiques d'appui à l'innovation et à l'internationalisation des entreprises brésiliennes.

Mots-clé: l'innovation technologique; exportations des entreprises brésiliennes; l'internationalisation des entreprises brésiliennes 